\title{
Article \\ Pilot Screening of Cell-Free mtDNA in NIPT: Quality Control, Variant Calling, and Haplogroup Determination
}

\author{
Alisa Morshneva ${ }^{1,2, *(\mathbb{D}}$, Polina Kozyulina ${ }^{1,2}$ (D) Elena Vashukova ${ }^{1,2}$, Olga Tarasenko ${ }^{1,2}$, Natalia Dvoynova ${ }^{2}$, \\ Anastasia Chentsova ${ }^{2}$, Olga Talantova ${ }^{1}$, Alexander Koroteev ${ }^{3,4}$, Dmitrii Ivanov ${ }^{3}$, Elena Serebryakova ${ }^{1}$, \\ Tatyana Ivashchenko ${ }^{1}$, Aitalina Sukhomyasova ${ }^{5,6}$, Nadezhda Maksimova ${ }^{6}$, Olesya Bespalova ${ }^{1}$, Igor Kogan ${ }^{1}$, \\ Vladislav Baranov ${ }^{1}$ and Andrey Glotov ${ }^{1,2}$ (D)
}

Citation: Morshneva, A.; Kozyulina, P.; Vashukova, E.; Tarasenko, O.; Dvoynova, N.; Chentsova, A.;

Talantova, O.; Koroteev, A.; Ivanov, D.; Serebryakova, E.; et al. Pilot Screening of Cell-Free mtDNA in NIPT: Quality Control, Variant Calling, and Haplogroup Determination. Genes 2021, 12, 743. https://doi.org/ $10.3390 /$ genes 12050743

Academic Editors:

Rossella Tomaiuolo and Paolo Cinelli

Received: 22 February 2021

Accepted: 11 May 2021

Published: 14 May 2021

Publisher's Note: MDPI stays neutral with regard to jurisdictional claims in published maps and institutional affiliations.

Copyright: (c) 2021 by the authors. Licensee MDPI, Basel, Switzerland. This article is an open access article distributed under the terms and conditions of the Creative Commons Attribution (CC BY) license (https:// creativecommons.org/licenses/by/ $4.0 /)$.
1 D.O. Ott Research Institute for Obstetrics, Gynaecology and Reproductology, Mendeleevskaya Line 3, 199034 St. Petersburg, Russia; polykoz@gmail.com (P.K.); vi_lena@list.ru (E.V.); olgatar777@mail.ru (O.T.); olga_talantova@mail.ru (O.T.); el.a.serebryakova@mail.ru (E.S.); tivashchenko2011@mail.ru (T.I.); shiggerra@mail.ru (O.B.); ikogan@mail.ru (I.K.); vsbar40@mail.ru (V.B.); anglotov@mail.ru (A.G.)

2 Ltd NIPT, Bolshoi V.O. 90, Building 2 lit. 3, 199106 St. Petersburg, Russia; 1.cosulya@gmail.com (N.D.); nastya.chentsova@gmail.com (A.C.)

3 St. Petersburg State Pediatric Medical University, 2 Litovskaya Street, 194100 St. Petersburg, Russia; alexkoroteev@mail.ru (A.K.); spb@gpma.ru (D.I.)

4 Center for Medical Genetics, Tobolskaya ul. 5, 194044 St. Petersburg, Russia

5 Molecular Medicine and Human Genetics, Research Laboratory, Medical Institute, M.K. Ammosov North-Eastern Federal University, 677007 Yakutsk, Russia; aitalinas@yandex.ru

6 Republican Hospital No. 1, National Medical Centre, Ministry of Public Health of the Sakha Republic, 677008 Yakutsk, Russia; nogan@yandex.ru

* Correspondence: 1195alisa@gmail.com

Abstract: Clinical tests based on whole-genome sequencing are generally focused on a single task approach, testing one or several parameters, although whole-genome sequencing (WGS) provides us with large data sets that can be used for many supportive analyses. In spite of low genome coverage, data of WGS-based non-invasive prenatal testing (NIPT) contain fully sequenced mitochondrial DNA (mtDNA). This mtDNA can be used for variant calling, ancestry analysis, population studies and other approaches that extend NIPT functionality. In this study, we analyse mtDNA pool from 645 cellfree DNA (cfDNA) samples of pregnant women from different regions of Russia, explore the effects of transportation and storing conditions on mtDNA content, analyse effects, frequency and location of mitochondrial variants called from samples and perform haplogroup analysis, revealing the most common mitochondrial superclades. We have shown that, despite the relatively low sequencing depth of unamplified mtDNA from cfDNA samples, the mtDNA analysis in these samples is still an informative instrument suitable for research and screening purposes.

Keywords: NIPT; foetal fraction; transportation; cfDNA; mtDNA; mitochondrial diseases; mitochondrial variants; SNPs; ClinVar; breast cancer; mtDNA haplogroups; population studies

\section{Introduction}

Discovery of the foetal DNA in maternal plasma made in 1997 by Denis Lo has marked the beginning of a new era in prenatal testing [1]. Since the introduction of non-invasive prenatal testing (NIPT) into clinical practice in 2011, initially as cell-free DNA (cfDNA)-based testing for foetal Down syndrome detection, the functionality of the method is constantly expanding [2]. Current diagnostic possibilities of NIPT cover a wide variety of foetal aberrations, such as common and rare trisomies, sex chromosome abnormalities (SCAs), deletions and microdeletions, duplications, copy number variants (CNVs), monogenic disorders, etc., and there is still place for improvement [2-5].

NIPT based on whole-genome sequencing (WGS) has especially high diagnostic and research potential since a large amount of sequenced cfDNA data enable many diagnostic 
instruments and can be further used for conducting various supporting studies for both the mother and foetus [6,7]. Low genome coverage remains the principal limitation that hampers the development of NIPT extensions. However, cfDNA fraction was reported to contain the full mitochondrial genome [8], compared to fairly low nuclear genomic DNA coverage. This can be explained by the higher copy number and relatively small size of mitochondrial DNA (16,569 bp) in comparison to genomic DNA (3 Gbp) [9]. Mitochondrial genes can undergo natural transfer to nuclear DNA so the nuclear copies of mtDNA (NUMTs) are formed [10]. NUMTs can be a source of contamination in mtDNA analyses [11] and compromise the results. Nevertheless, as mentioned, the low nuclear genome coverage in NIPT samples reduces the impact of such effects.

The fact that mitochondrial DNA (mtDNA) in NIPT samples is fully covered opens the door to variant calling and mtDNA analysis across many samples. The pool of mtDNA in cfDNA fraction is heterogeneous and contains fragmented mtDNA from apoptotic cells of different types and, in case of pregnancy, foetal mtDNA [12]. Due to its prokaryotic origin, mtDNA has high inflammatory potential since it is similar to bacterial DNA and triggers an anti-pathogen response [13]. MtDNA, along with ATP and cytochrome-c, belongs to damage-associated molecular pattern molecules (DAMPs) working as endogenous danger signals and releasing from damaged mitochondria of dying cells or injured tissues [14,15]. The release of mitochondrial DAMPs into the circulation is a marker of systemic inflammatory responses and a direct link between elevated cell-free mtDNA (cf-mtDNA) level and chronic inflammation in patients with type 2 diabetes [16]. Alterations in the cfmtDNA level were also reported for many chronic diseases and pathologic states, such as sepsis, injuries, diabetes, coronary heart diseases, Parkinson's disease and Alzheimer's disease [17-21].

Due to continuous apoptosis of placental trophoblasts, pregnancy can be viewed as a pseudoinflammatory state [22]. As a result, mtDNA is detectable in maternal plasma in normal pregnancy and increased in cases of many pregnancy complications [23-26]. This increases the interest of clinicians in cf-mtDNA fraction due to its potential application in diagnostics of pregnancy pathologies such as preterm birth that is known to be tightly connected with inflammation [27].

Furthermore, a lot of mitochondrial variants are proved or presumed to be associated with various diseases. These variants might affect energy metabolism, production of reactive oxygen species (ROS), ATP synthesis, calcium signalling and apoptosis but the exact mechanisms behind the observed associations are still to be uncovered [28-31]. Mitochondrial mutations underlie such pathologies as Leber hereditary optic neuropathy (LHON), Leigh syndrome (LS), neurogenic muscle weakness, ataxia and retinitis pigmentosa (NARP) and many others [32-34]. Since cells contain many copies of mitochondria, one cell can contain both mutated and normal mtDNA - this heterogenic state is known as heteroplasmy [35]. Heteroplasmic state is typical for most of the mitochondrial variants, including pathogenic ones and disease severity is often associated with the amount of mutated mtDNA in cells [36].

Apart from its diagnostic capabilities, mtDNA is of great interest for population and phylogenetic studies since it is not as conservative as nuclear DNA and deteriorates much faster with an average mutation rate of $\sim 2.7 \times 10^{-5}$ per base per 20-year generation [37] against $\sim 2.5 \times 10^{-8}$ per base per generation mutation rate of genomic DNA [38]. Notably, the speed of mutation varies between different regions of mtDNA, reaching the maximum in the non-coding control region, which accumulates the majority of all mitochondrial SNPs [39]. Non-coding D-loop region $(16,024-576 \mathrm{bp})$ is a hot spot for mtDNA alterations, containing two hypervariable regions (HV1 at 16,024-16,383 bp and HV2 at 57-372 bp) [40]. High mutability of mtDNA and its maternal inheritance make mtDNA exceptionally useful as a molecular clock.

MtDNA along with $Y$ chromosome is the common trackers of human ancestry [41,42], both having the uniparental type of inheritance and representing maternal and paternal lineage respectively. MtDNA carries a particular combination of variants inherited from a 
common ancestor, defining its haplotype [43]. Human mitochondrial phylogenetic trees have these mitochondrial haplotypes as the leaves, which can be assigned to mitochondrial haplogroups [44]. Mitochondrial haplogroups are widely used to track the population origins and genetic structure. This can be especially interesting for exploring the structure of mixed populations.

There are works demonstrating the possibility of using low-coverage WGS sequencing NIPT data for population studies, but they are mostly focused on genomic DNA [45,46].

In this study, we work with samples from different regions of Russia, including for the most part Northwestern, Central, Volga-Ural regions and Yakutia, which is populated by the indigenous ethnic groups of the Mongoloid (Asian) race (54.1\%): Yakuts and minor groups of Evenks, Evens, Dolgans, Yukagirs, Chukchi and non-indigenous ethnic groups (45.9\%), including the Caucasians Russians and Ukrainians. Yakuts is one of the Turkic ethnic groups that emerged as a mixture of Turkic people and indigenous people [47,48]. Phylogenetic analysis has revealed that indigenous ethnic groups belong to the E Asian clade or the Beringian-American clade, including native Americans $[49,50]$. Thus the heterogeneity of ethnic groups in our dataset can be of interest for both populational and clinical studies.

Analysis of mtDNA underlies many medical and genetic tests. Apart from maternal ancestry testing, based on mtDNA haplogroup determination [51], there are genetic diagnostic tests for mitochondrial diseases, mainly running on mtDNA whole genome sequence [52] or a panel of common mtDNA point mutations associated with various mitochondrial disorders [52,53].

In this study, we explore the utility of using NIPT data for mtDNA studies. Given the increasing popularity of NIPT, the possibility of the analysis of mtDNA from cfDNA data is quite promising.

\section{Materials and Methods}

\subsection{Data}

In this study, we processed 645 samples from patients with both normal and pathologic pregnancies subjected to NIPT analysis in The Research Institute of Obstetrics, Gynecology and Reproductology named after D.O. Ott. Samples were transported from different regions of Russia: 397 samples from Northwestern district (mostly Saint-Petersburg), 120 from Central district, 63 from Volga-Ural district, 49 from Yakutia and 10 from North Caucasian districts. Southern and Far Eastern districts are presented by 4 and 2 samples respectively. All women signed informed consent for studies and processing of personal data, including medical history data. The study was performed in accordance with the Declaration of Helsinki.

\subsection{Plasma DNA Isolation}

Blood samples were collected either in tubes with 0.5 M EDTA solution $(\mathrm{pH}=8.0)$ (Greiner Bio One, Kremsmünster, Austria) or Cell-Free DNA Streck ${ }^{\mathrm{TM}} \mathrm{BCT}^{\circledR}$ blood collection tubes (cfDNA BCT, La Vista, NE, USA). EDTA tubes were centrifuged $30 \mathrm{~min}$ after the blood sampling at $2000 \mathrm{~g}$ for $10 \mathrm{~min}$ at $4{ }^{\circ} \mathrm{C}$ to get plasma and then centrifuged the plasma at $16,000 \mathrm{~g}$ for $10 \mathrm{~min}$ at $4{ }^{\circ} \mathrm{C}$. Streck tubes were centrifuged on arrival from regions at $1600 \mathrm{~g}$ for $10 \mathrm{~min}$ at room temperature to get plasma and then the plasma was centrifuged at $16,000 \mathrm{~g}$ for $10 \mathrm{~min}$ at room temperature. For plasma from Streck tubes, we used a Proteinase $\mathrm{K}$ treatment step ( $\geq 30 \mathrm{mAU} / \mathrm{mL}$ digest) at $60^{\circ} \mathrm{C}$ in the presence of SDS for $1 \mathrm{~h}$ when extracting cf-DNA. For DNA extraction we used 'MagMAX Cell-Free DNA Isolation Kit' (Thermo Fisher Scientific Inc., Waltham, MA, USA) following the manufacturer's instructions.

\subsection{Buffy Coat Analysis}

In order to explore the differences between mtDNA pools of buffy coat and cfDNA from blood plasma, we have sequenced DNA, extracted from several buffy coats stored 
either in EDTA $(n=4)$ or Streck Cell-Free DNA BCT blood collection tubes $(n=4)$. Each one of buffy coat DNA samples has been paired with the corresponding cfDNA sample. DNA samples from the buffy coats were isolated by salt-out extraction with some modifications [54]. Briefly, buffy coats were resuspended in nuclei lysis buffer $(10 \mathrm{mM}$ Tris- $\mathrm{HCl}, 400 \mathrm{mM} \mathrm{NaCl}$ and $2 \mathrm{mM} \mathrm{Na}$ EDTA, $\mathrm{pH}$ 8.2). The cell lysates were digested $5 \mathrm{~h}$ at $55{ }^{\circ} \mathrm{C}$ with $0.02 \mathrm{~mL}$ of $10 \%$ SDS, $0.4 \mathrm{~mL}$ of a proteinase $\mathrm{K}$ solution $(10 \mathrm{mM}$ Tris- $\mathrm{HCl}$, $0.15 \mathrm{M} \mathrm{NaCl}$ and $1 \mathrm{mM} \mathrm{Na} 2 \mathrm{EDTA}, \mathrm{pH} 8.0$ ) with $21 \mathrm{mg}$ proteinase $\mathrm{K}$. After digestion was complete, $1 \mathrm{~mL}$ of $5 \mathrm{M} \mathrm{NaCl}$ was added and shaken vigorously for $15 \mathrm{~s}$. Then one volume of chloroform was added and shaken for $10 \mathrm{~min}$ followed by centrifugation at 10,000 rpm for $10 \mathrm{~min}$. The upper aqueous phase was transferred to a fresh tube. Then one volume of chloroform was added again and shaken for $5 \mathrm{~min}$ followed by centrifugation at 10,000 rpm for $5 \mathrm{~min}$. The upper aqueous phase was transferred to a fresh tube. Two volumes of room temperature absolute ethanol were added and the tubes inverted several times until the DNA precipitated. The DNA pellet was washed with $70 \%$ ethanol twice, and was collected at the bottom of the tube by centrifugation at $5000 \mathrm{rpm}$ for $5 \mathrm{~min}$ and dried at room temperature. The DNA was allowed to dissolve in $0.2 \mathrm{~mL}$ TE. Before preparing the libraries, DNA fragmentation was performed using the Diagenode Bioruptor UCD-200 according to the manufacturer's recommendations.

\subsection{Library Preparation \& Sequencing}

The library preparation step involved three steps: blunt-end ligation, barcode ligation and amplification. We used the 'Ion Plus Fragment Library Kit' (Thermo Fisher Scientific Inc., USA) protocol with some proprietary modifications (patent G01N 33/48, C40B 50/00, G06F 19/20, C12Q1/68). DNA concentrations were measured with 'Qubit 2.0' fluorimeter (Invitrogen, Carlsbad, CA, USA), using 'Qubit dsDNA HS Assay Kit' (Thermo Fisher Scientific Inc., USA). The quantity of libraries required for sequencing was determined according to the manufacturer's protocol (Thermo Fisher Scientific Inc., USA). Quality of samples has been tested with capillary electrophoresis 'TapeStation Instrument' (Agilent technologies, Santa Clara, CA, USA), using 'High Sensitivity D1K ScreenTape' and 'High Sensitivity D1K Reagents' (Agilent technologies, USA). 'Ion Chef System' (Thermo Fisher Scientific Inc., USA) has been used for sample loading with 'Ion 540 Kit-Chef' (Thermo Fisher Scientific Inc., USA) following the manufacturer's instructions. We used microchips 'Ion 540 Chip' (Thermo Fisher Scientific Inc., USA) following the manufacturer's instructions. Sequencing has been performed with 'Ion Torrent S5' (Thermo Fisher Scientific Inc., USA) with the average coverage of 3-4 million reads per sample. The preliminary processing of sequencing results was performed using Torrent Suite software v5.12.2 (ThermoFisher Scientific Inc., USA). The bam files were filtered by sequencing quality (trimming quality cutoff 15) and barcodes and adapters trimmed off.

\subsection{Variant Calling and ClinVar Annotation}

For each sample, we extracted mtDNA reads from Ion Torrent S5 generated WGS bam files using Samtools [55]. Mitochondrial variants were called using MuTect2 from GATK4 $[56,57]$ in the mitochondria mode. Variants recovered in VCF files were filtered by sequencing depth $(<5)$ for further analysis to exclude variants with low depth; variants located within homopolymers (of length 4 and more) were filtered out with VCFPolyX [58]. For variant annotation, we used the ClinVar database of 16 March 2020 [59] and VariantAnnotator from GATK4 with default parameters and hg19 as a reference genome [60].

\subsection{Haplogroup Assignment}

Haplogroups of mtDNA were assigned with HaploGrep2 [61] based on the sets of variants found in individual samples, samples with the lowest haplogroup confidence score (0.5) were discarded. 


\section{Results}

\subsection{MtDNA Pool Is Better Presented in cfDNA Samples from Streck Collection Tubes}

At the outset, we conducted a quantitative analysis of mtDNA fraction of $645 \mathrm{cfDNA}$ samples of pregnant women. MtDNA content was measured for each sample as the ratio of mitochondrial reads to the total number of reads in the sample. The number of mitochondrial reads varies from 16 to 5536, with a median of $276 \mathrm{mtDNA}$ reads per sample. The mtDNA content of different samples varies by two-three orders of magnitude and generally is higher in samples collected to Streck tubes than in samples collected to EDTA tubes (Figure 1A). The same trend can be observed for the mtDNA coverage: the vast majority of samples with more than $75 \%$ mtDNA coverage belongs to the Streck group (Figure 1B). In total, $57 \%$ of all samples have mtDNA coverage exceeding $75 \%$. The mean sequencing depth is also demonstrating the same trend. The mean sequencing depth of different samples varies from 1 to 40 (Figure 1C). In general, Streck samples have a better quality of sequenced mtDNA material.

A
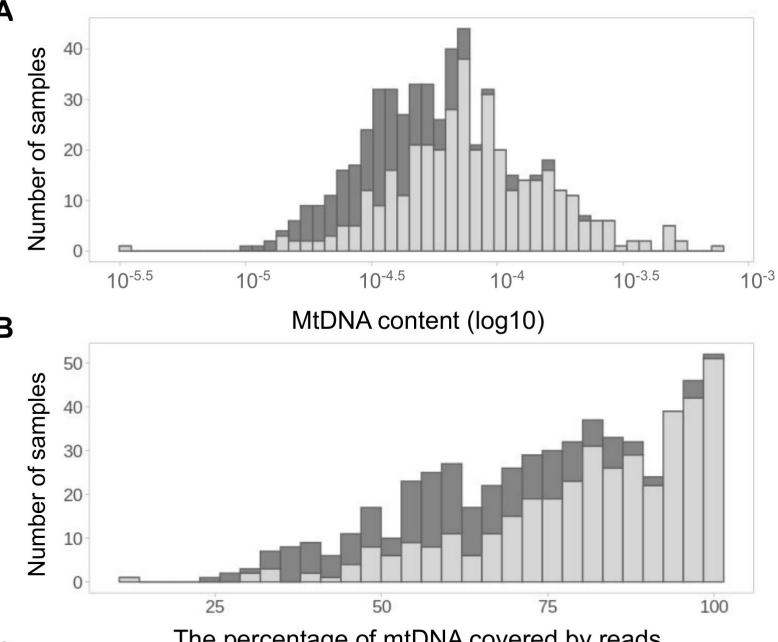

C

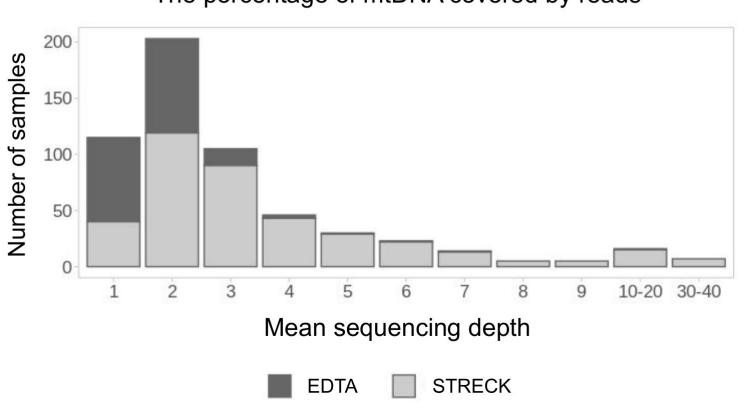

Figure 1. The quantitative analysis of the mtDNA pool in samples. MtDNA content (A), mtDNA coverage (B) and sequencing depth (C) distribution in samples collected to EDTA (dark-grey) and Streck (light-grey) sample tubes.

3.2. Variant Calling Reveals a Number of Non-Ancestral Mitochondrial Variants Frequent within the Russian Population

All 645 mtDNA samples have been processed for mitochondrial variant calling. Variant calling was performed using MuTect2 from GATK4 in the mitochondria mode, which basically works like a somatic variant caller. From these samples we called 32962 variants. To reduce the impact of sequencing errors, we performed a two-step filtration (Table 1). First of all, variants with sequencing depth of less than 5 were filtered out. The depth threshold for mitochondrial variants is usually lower than the one for genomic variants since mitochondrial variants can be presented in a small fraction of reads due to heteroplasmy and high copy number. Next, we filtered out the variants found within homopolymers since the semiconductor sequencing platform is prone to errors in homopolymer regions. 
We excluded variants within polynucleotide repeats of the length 4 and more, which were mostly indels. Due to strict filtering conditions, we missed a certain percentage of the true variants, however, we were still able to successfully detect a good part of them.

Table 1. The number of point mutations (SNPs) and indels before and after two-step filtration.

\begin{tabular}{cccc}
\hline & Total Number of Variants & Indels & SNPs \\
\hline Total & 32,962 & 21,416 & 11,546 \\
Depth filtering & 22,017 & 17,035 & 4982 \\
Homopolymer filtering $(\geq 4)$ & 14,681 & 10,479 & 4202 \\
Homopolymer filtering $(\geq 3)$ & 8969 & 6450 & 2519 \\
\hline
\end{tabular}

Remaining pool of variants (14681) is represented by 7493 distinct variants. Most of them $(96.2 \%)$ have a frequency of less than $1 \%$ (Figure $2 \mathrm{~A}$ ) and only 10 variants exceed $10 \%$ frequency. Among the detected variants, 6 have population frequency exceeding $15 \%$ : variants m.9769delT (23.3\%), m.15326A >G (22.3\%), m.750A $>\mathrm{G}(20.9 \%), \mathrm{m} .2706 \mathrm{~A}>\mathrm{G}$ $(18.8 \%)$, m.12272delA $(15.7 \%), \mathrm{m} .263 \mathrm{~A}>\mathrm{G}(15.0 \%)$ are the most frequent in all explored geographic regions. A majority of them belong to ancestral variants, common across all lineages and especially frequent in lineages of superclade $M$, including lineages $C$ and $\mathrm{D}$ [62].

A

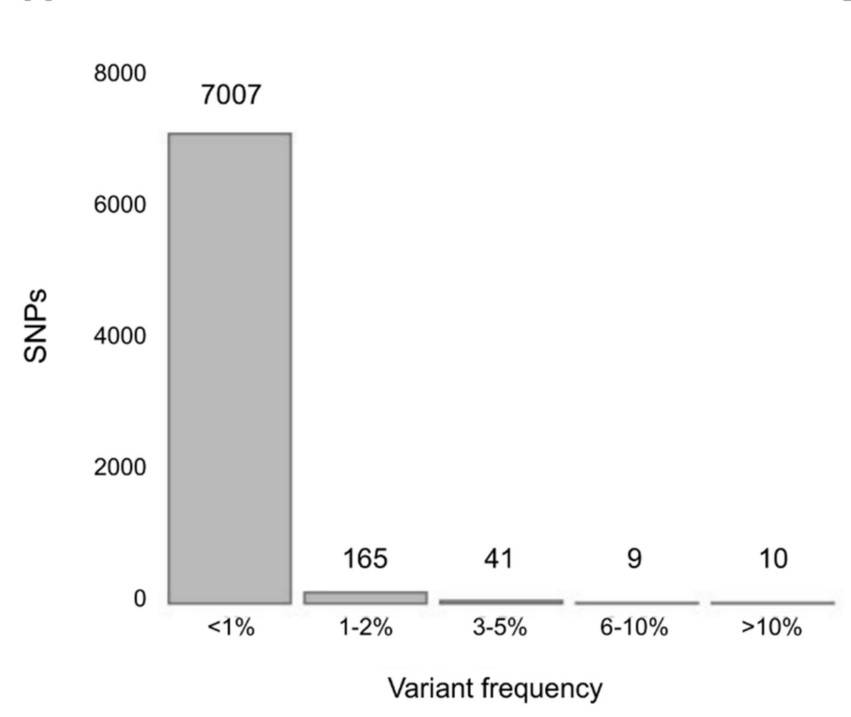

B

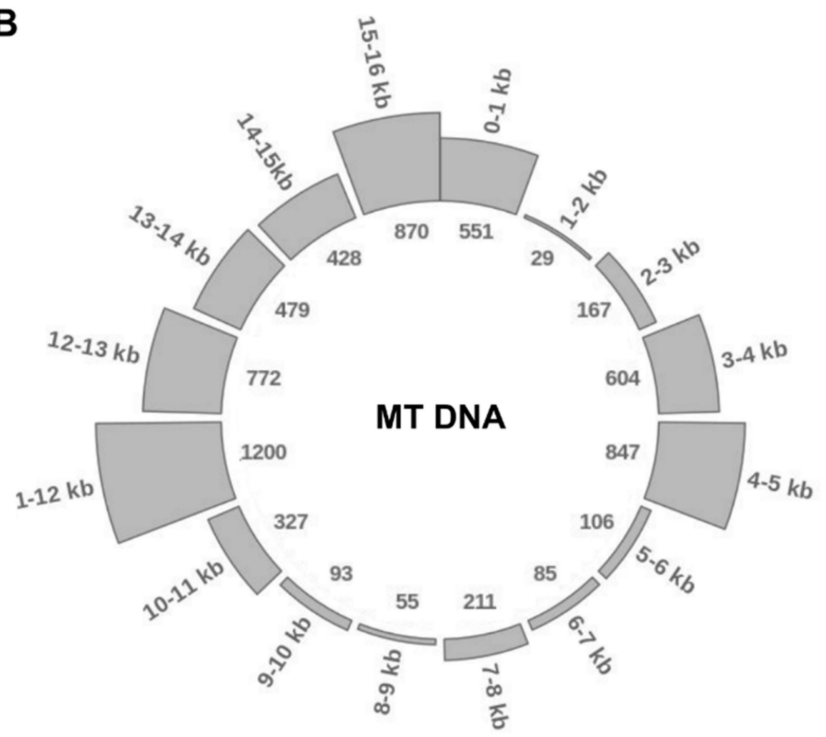

Figure 2. Variant distribution: frequency and location in the mitochondrial genome. (A) Distribution of distinct variants according to their population frequency (by the percentage of samples carrying the particular variant). (B) Distribution of variants throughout the mitochondrial genome. Figures outside the circle mark position in the mitochondrial genome (16 kb mtDNA has been divided into 16 sections per $1 \mathrm{~kb}$ ), figures in the inner circle represent the number of variants in every section.

Aside from ancestral variants, reasonably frequent in all populations, we selected the top-5 of non-ancestral point (Table 2) and indel (Table 3) variants frequent in our data. For indels, we used stricter homopolymer filtering $(\geq 3)$ since most of the frequent indels are located within homopolymers of length 3 and more and can stem from sequencing errors (Table 1). 
Table 2. Top-5 most frequent non-ancestral point variants. Columns from left to right: mtDNA sequence variant, variant frequency (number of patients and frequency).

\begin{tabular}{cc}
\hline mtDNA Variant & Patients \\
\hline $\mathrm{m} .15301 \mathrm{G}>\mathrm{A}$ & $43(6.7 \%)$ \\
$\mathrm{m} .489 \mathrm{~T}>\mathrm{C}$ & $36(5.6 \%)$ \\
$\mathrm{m} .10400 \mathrm{C}>\mathrm{T}$ & $36(5.6 \%)$ \\
$\mathrm{m} .14783 \mathrm{~T}>\mathrm{C}$ & $34(5.3 \%)$ \\
$\mathrm{m} .15452 \mathrm{C}>\mathrm{A}$ & $29(4.5 \%)$ \\
\hline
\end{tabular}

Table 3. Top-5 most frequent non-ancestral indels. Columns from left to right: $\mathrm{mtDNA}$ sequence variant, number of patients and frequency.

\begin{tabular}{cc}
\hline mtDNA Variant & Patients \\
\hline m.9906delG & $81(12.6 \%)$ \\
m.10151delA & $44(6.8 \%)$ \\
m.9916delC & $38(5.6 \%)$ \\
m.2193delT & $28(4.3 \%)$ \\
m.9808insT & $27(4.2 \%)$ \\
\hline
\end{tabular}

Since most of these variants are not presented in databases, we also highlight the top-5 of ClinVar SNPs (Table 4).

Table 4. Top-5 most frequent non-ancestral SNPs presented in ClinVar database. Columns from left to right: mtDNA sequence variant, variant ID (rs), variant ID (ClinVar), clinical significance (ClinVar), diagnosis (ClinVar), number of patients and frequency.

\begin{tabular}{|c|c|c|c|c|c|}
\hline mtDNA Variant & rs ID & ClinVar ID & Clinical Significance & Diagnosis (ClinVar) & $\begin{array}{l}\text { Number of } \\
\text { Patients }\end{array}$ \\
\hline $\mathrm{m} .15301 \mathrm{G}>\mathrm{A}$ & 193302991 & 140591 & $\begin{array}{c}\text { Conflicting interpretations } \\
\text { of pathogenicity }\end{array}$ & Familial cancer of breast & $43(6.7 \%)$ \\
\hline $\mathrm{m} \cdot 14783 \mathrm{~T}>\mathrm{C}$ & 193302982 & 140588 & $\begin{array}{c}\text { Conflicting interpretations } \\
\text { of pathogenicity }\end{array}$ & Familial cancer of breast & $34(5.3 \%)$ \\
\hline m.15452C $>$ A & 193302994 & 143925 & Benign & $\begin{array}{l}\text { Neoplasm of ovary / } \\
\text { Leigh syndrome }\end{array}$ & $29(4.5 \%)$ \\
\hline m.3010G $>A$ & 3928306 & 441149 & Drug response & Not provided & $28(4.3 \%)$ \\
\hline m.13708G >A & 28359178 & 9696 & Benign & $\begin{array}{l}\text { Leber's optic } \\
\text { atrophy/Leigh syndrome }\end{array}$ & $10(1.6 \%)$ \\
\hline
\end{tabular}

As expected, the distribution of detected variants throughout the mitochondrial genome is not uniform. There are so-called 'hot spots' in 3-5, 11-13 and 15-16 kb (Figure 2B), carrying $66.9 \%$ of all variants and 'cold spots' in 1-2, 5-7 and $8-10 \mathrm{~kb}$, carrying only $5 \%$ of variants. Variants are accumulating in upstream and downstream gene regions (intergenic variants).

Due to strict filtering conditions, a certain percentage of the true variants are inevitably missing, especially in homopolymeric regions. Nevertheless, the proportions of variants in individual sections of the mitochondrial genome are not affected by filtering (Figure S1).

\subsection{The Buffy Coat and cfDNA Contain Different Pools of mtDNA}

In order to assess the contribution of degraded blood cells to the overall mtDNA pool, we compared mtDNA pools between cfDNA samples and corresponding buffy coat samples. Sequenced data obtained from buffy coat DNA and cfDNA samples proceeded through the same steps: extraction of mtDNA reads, estimation of mtDNA rate, variant calling and filtering of homopolymer variants.

The comparison of such parameters as mtDNA content, number of called variants and percentage of heteroplasmy within pairs has revealed different trends for samples stored 
in EDTA and Streck sample tubes. Within these groups of sample pairs (the EDTA group and the Streck group), pairs demonstrated similar parameters. Therefore, we averaged the values within each group and compared the common characteristics of mtDNA pools from buffy coat and cfDNA separately for EDTA and Streck (Figure 3A).

A
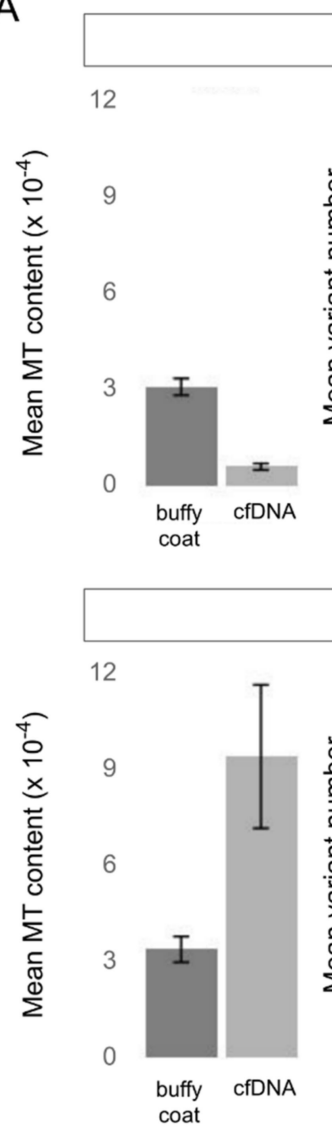

EDTA

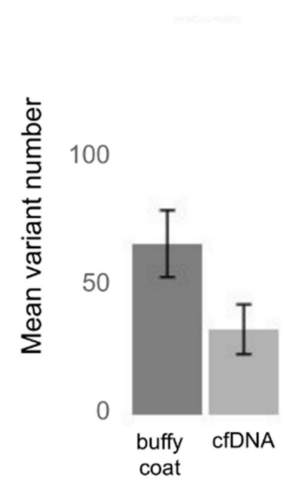

STRECK

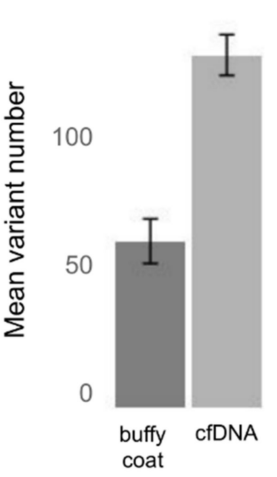

B

30

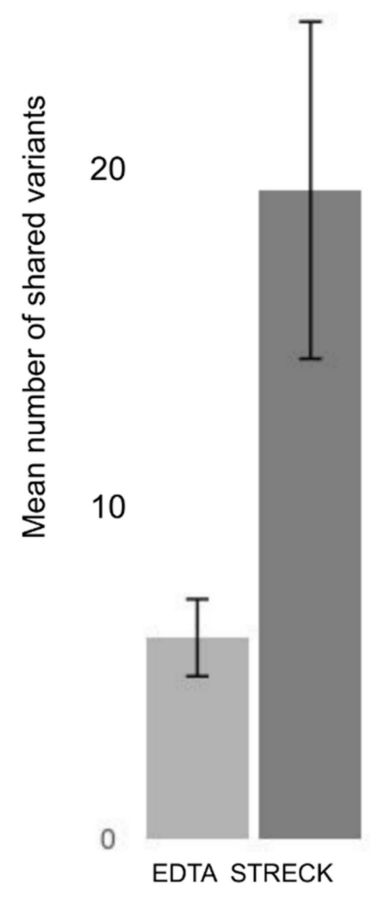

Figure 3. The comparison between mtDNA pools of buffy coat and cfDNA from blood plasma in samples with different transportation conditions (transported in EDTA (blood plasma) or Streck (whole blood) sample tubes). The bars represent the mean values for the buffy coat—cfDNA pairs $(n=4)$; error bars indicate the standard error of the mean (SEM). (A) Average mtDNA content (the ratio of mtDNA reads to nuclear DNA reads averaged over all samples), the average number of called mitochondrial variants (homopolymer variants were filtered out) and the average percentage of heteroplasmy in buffy coat and cfDNA samples. (B) The average number of the mitochondrial variants shared by mtDNA pools of buffy coat and cfDNA (homopolymer variants were filtered out).

Our results show that cfDNA extracted from samples transported as blood plasma (EDTA) contains significantly less mtDNA than DNA from buffy coat and therefore have a smaller set of mitochondrial variants, while cfDNA extracted from samples transported as whole blood (Streck) are enriched with mtDNA and consequently carry more variants. The heteroplasmy level has also demonstrated the same trend. However, despite lower mtDNA content, the mtDNA pool in EDTA samples is still enough for the analysis.

To evaluate the similarity of mtDNA pools from buffy coat and cfDNA, we estimated the number of variants they share. According to our results, sets of mitochondrial variants called from buffy coat and cfDNA of one individual are quite different and have a little overlapping, suggesting that buffy coat and cfDNA contain different pools of mtDNA which can be attributed to the mixed origin of cf-mtDNA. MtDNA from the buffy coat samples stems from the blood cells, representing the limited set of cell populations. Notably, the Streck samples of buffy coat DNA and cfDNA share more variants, indicating that degrading blood cells make a significant contribution to the pool of cf-mtDNA (Figure 3B). 
On average, Streck samples share three times more variants. Thus the difference between two types of sample tubes can be essential to downstream NIPT analysis and needs further investigation.

\subsection{Long Transportation Results in an Increase of mtDNA Content Which Leads to the Lower} Fetal Fraction in Samples

Our study includes samples from remote regions, so to check the possibility of blood cell DNA leakage into a cell-free fraction we explored the effect of long transportation on mtDNA content and hence on the number of called variants. For different samples, time of transportation varies from 1 to 14 days (Figure 4A). Content of mtDNA in samples increases over time (Figure 4B).

A
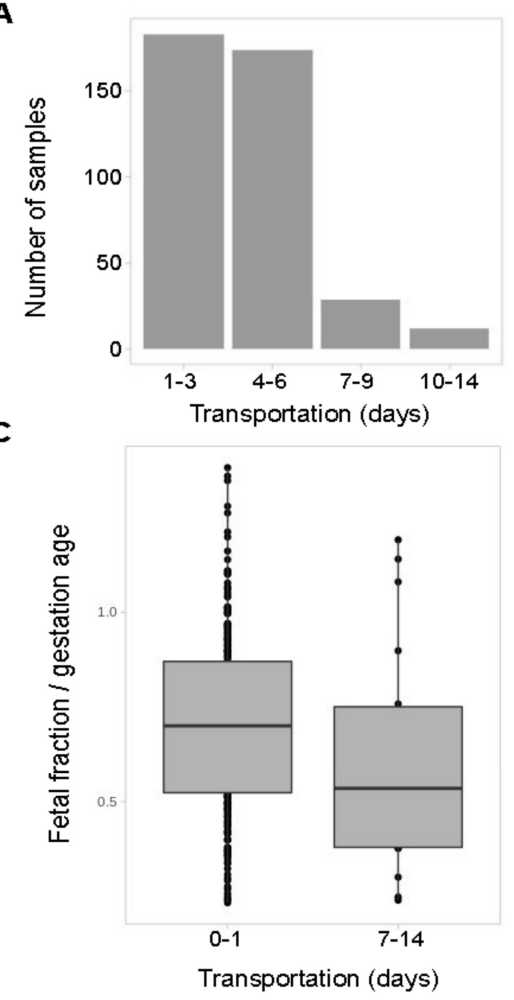

E
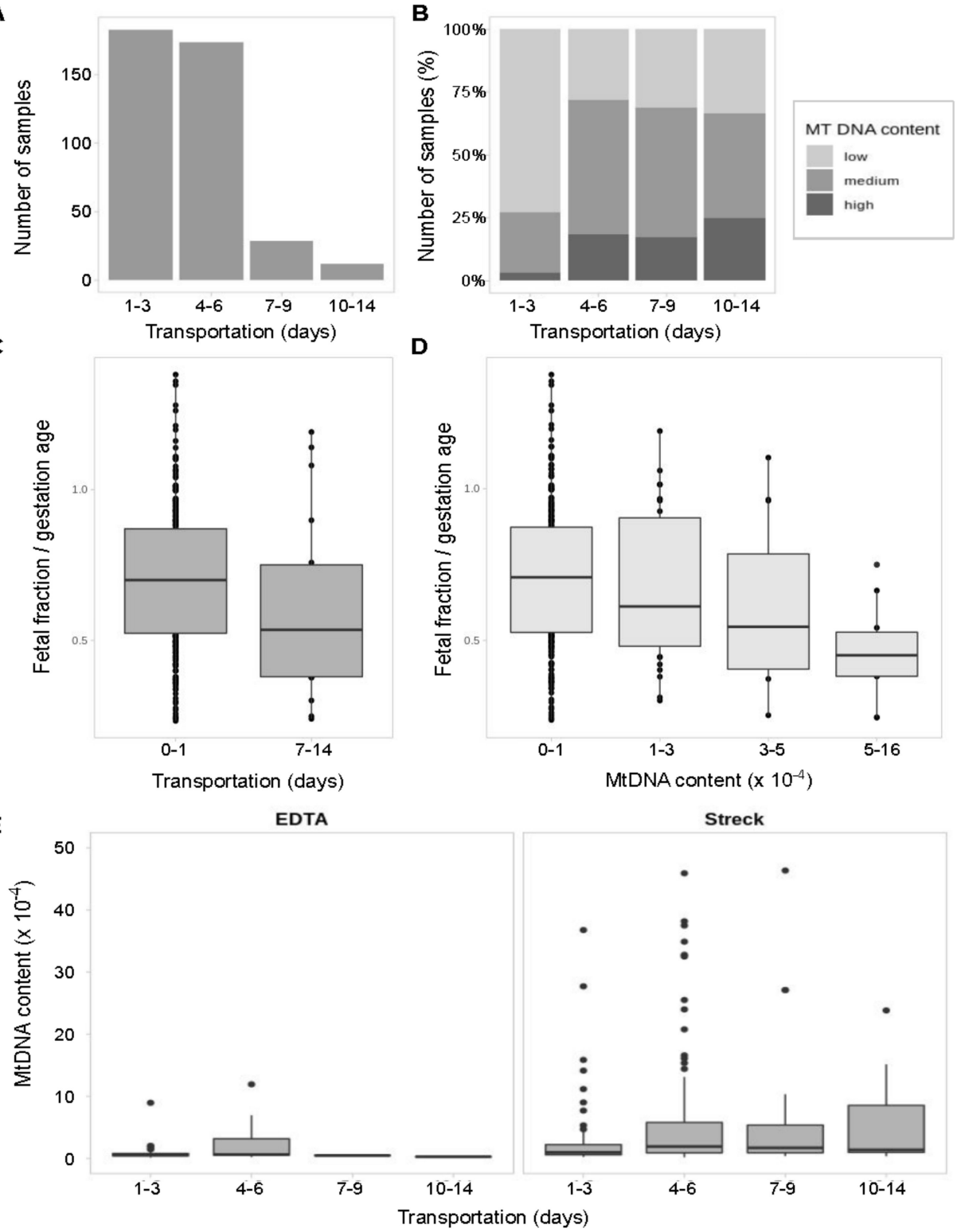

D

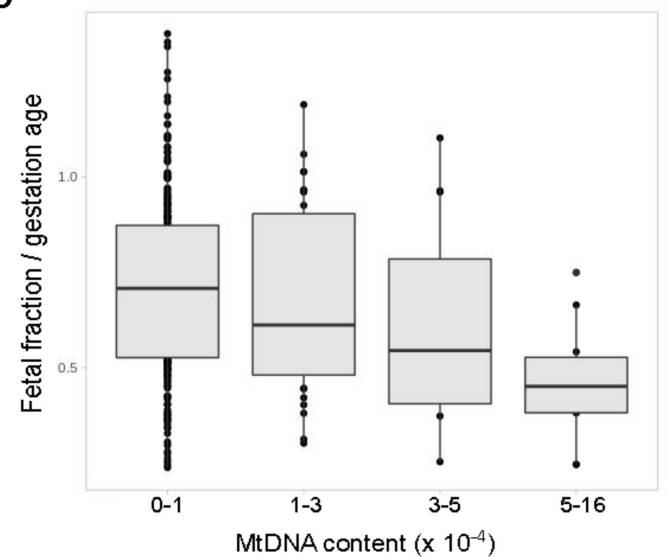

MtDNA content $\left(x 10^{-4}\right)$

$$
\text { (n) }
$$

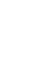


Among the samples shipped within $72 \mathrm{~h}$, samples with low mtDNA content prevail and samples with high amounts of mtDNA are almost never met. After that 72-h threshold, the fraction of samples enriched with mtDNA rises. Notably, this mtDNA enrichment is observed only in Streck Cell-Free DNA BCT blood collection tubes storing whole blood. As expected, EDTA tubes storing blood plasma show equal mtDNA content over time (Figure 4C) supporting the hypothesis that DNA from degraded blood cells accumulates in Streck Cell-Free DNA BCT blood collection tubes over time.

The previous studies $[63,64]$ have explored the stability of DNA in EDTA and Streck collection tubes but only for the short periods of $72 \mathrm{~h}$ and less. We assumed that the longer the transportation time the more blood cells get degraded, which might negatively affect the foetal fraction level and thus potentially affect the quality of NIPT results. To check this out, we evaluated the difference between the foetal fraction size in samples shipped under and over 7 days. Indeed, there is a downward trend in the foetal fraction size after 7 days of transportation (Figure 4D) and the statistically significant decrease of foetal fraction level in samples with high mtDNA rate (Figure 4E).

\subsection{Analysis of Population Frequencies Reveals Differences in Top-Frequent Variants between Regions of Russia}

To explore the cross-regional differences, we split samples into groups according to their origin. The vast majority of samples were taken from Central $(46.9 \%)$ and Northwestern (31.8\%) regions, 10.2\% were transferred from Yakutia, $8.49 \%$ from Volga-Ural region, the rest $2.55 \%$ of samples ('Others' category) were transferred from Southern, North Caucasian and Far Eastern regions (Figure 5A).

A

B
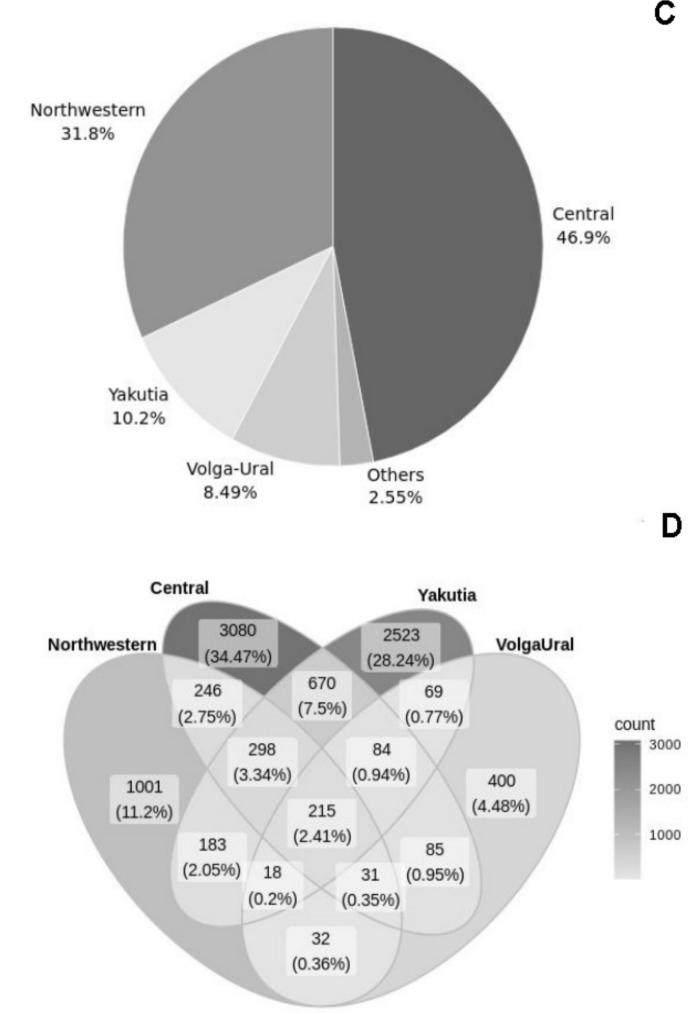

C

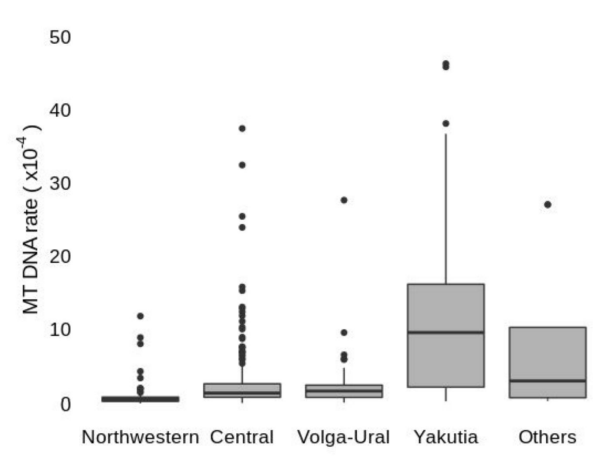

D

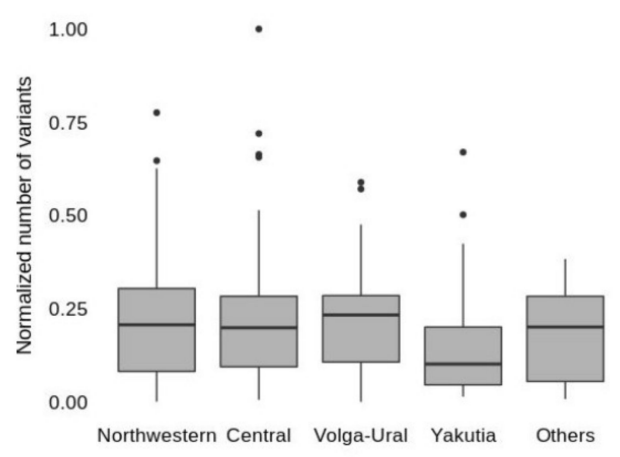

Figure 5. Geographic origin of explored samples. (A) Distribution of samples according to geographic region (Others include Southern, Far Eastern and North Caucasian regions, presented with a minor fraction of samples). (B) A Venn diagram representing the intersection between sets of variants in four regions: Northwestern, Central, Volga-Ural and Yakutia. Figures represent the number of distinct variants in every section and the percentage of the total number of variants. (C) Distribution of samples in every region according to mtDNA content. (D) Distribution of samples in every region by the number of variants, normalised to mtDNA content. 
The variant intersection between Central, Northwestern, Yakutia and Volga-Ural regions has revealed only 215 common variants, which is only $2.4 \%$ of all detected variants (Figure 5B). The most frequent variants in each region belong to this $2.4 \%$ of shared variants and mostly presented by frequent ancestral variants, so explored regions do not have unique mitochondrial markers. However, the frequency of some variants in Yakutia reaches over $70 \%$ while in other regions these variants do not exceed $10 \%$ frequency or are even absent (Table 5). Non-ancestral variants frequent in the Yakutian population are included in the top of the most frequent variants for lineage M in MITOMAP (which refers to Mongolian ancestry), confirming the validity of our results.

Table 5. Top-3 non-ancestral variants that are frequent in Yakutia and rare in other regions. Columns from left to right: mtDNA sequence variant, the frequency of the variant in each region (\% from the number of samples in each region), the total number of patients carrying the variant.

\begin{tabular}{ccccccc}
\hline $\begin{array}{c}\text { DNA Seq } \\
\text { Variant }\end{array}$ & $\begin{array}{c}\text { Central } \\
\mathbf{( \% )}\end{array}$ & $\begin{array}{c}\text { Northwestern } \\
\mathbf{( \% )}\end{array}$ & $\begin{array}{c}\text { Volga-Ural } \\
\mathbf{( \% )}\end{array}$ & $\begin{array}{c}\text { Yakutia } \\
\mathbf{( \% )}\end{array}$ & $\begin{array}{c}\text { Others } \\
\mathbf{( \% )}\end{array}$ & $\begin{array}{c}\text { Number of } \\
\text { Patients }\end{array}$ \\
\hline $\mathrm{m} .15301 \mathrm{G}>\mathrm{A}$ & 1.81 & 8.00 & 0.0 & 79.17 & 0.00 & $54(8.4 \%)$ \\
\hline $\mathrm{m} .10400 \mathrm{C}>\mathrm{T}$ & 0.00 & 2.67 & 2.5 & 75.00 & 0.00 & $41(6.4 \%)$ \\
\hline $\mathrm{m} .12704 \mathrm{TC}>\mathrm{T}$ & 1.36 & 3.33 & 0.0 & 47.92 & 0.00 & $31(4.8 \%)$ \\
\hline
\end{tabular}

Since Northwestern and Central regions are widely presented in our data, the large sets of variants for these regions were quite expected. To the contrary, $40 \%$ of detected variants originate from Yakutia, which accounts for only 10\% of the samples. Since we established that long transportation affects the number of detected variants due to increased mtDNA content, we explored mtDNA content in samples from different regions. Distribution of mtDNA content (Figure 5C) between regions is in line with the distribution of the variants. Increased mtDNA content is observed in the most remote regions, so despite the low number of samples, these regions are making a large proportion of variants. To ensure that there is no real difference in the number of variants between regions, we normalised the number of variants to mtDNA content for each sample (Figure 5D).

\subsection{MtDNA Haplogroup H along with C, D and U Are the Most Frequent among Explored Samples}

Haplogroups of mtDNA for individual samples were identified with HaploGrep [61] based on the filtered sets of variants. Variants located within homopolymer regions were filtered out as described in Section 3.2.

Analysis of haplogroup frequencies at the level of clades has revealed that haplogroups $\mathrm{H}(41.2 \%), \mathrm{C}(13.7 \%), \mathrm{D}(11.1 \%)$ and $\mathrm{U}(10.5 \%)$ are prevalent (Figure $6 \mathrm{~A})$. The rest of the haplogroups do not exceed 10\% frequency- $\mathrm{J}(9.2 \%), \mathrm{T}(5.2 \%), \mathrm{K}(2.6 \%)$ and minor haplogroups M, N, W, B and I, presented by isolated findings and together make up $6 \%$ of all samples. To improve the reliability of the results in view of the low coverage data, samples with the lowest haplogroup confidence score (0.5) were discarded. These were mostly samples presented by less than 40 variants.

Next, we explored how this distribution changes from region to region (Figure 6B). We revealed that haplotypes of $\mathrm{H}$ superclade are top-frequent in all regions except for Yakutia, where most samples have haplogroups of superclades C (45\%) and D (33\%).

For some samples enriched with mtDNA we determined full haplogroup with high quality score: 19 samples with the quality score exceeding $85 \%$ and 4 variants around 90\%-H2a1c (91\%), J1c2 (90\%), D4I2a1 (89\%), H1c4b (89\%). 
A

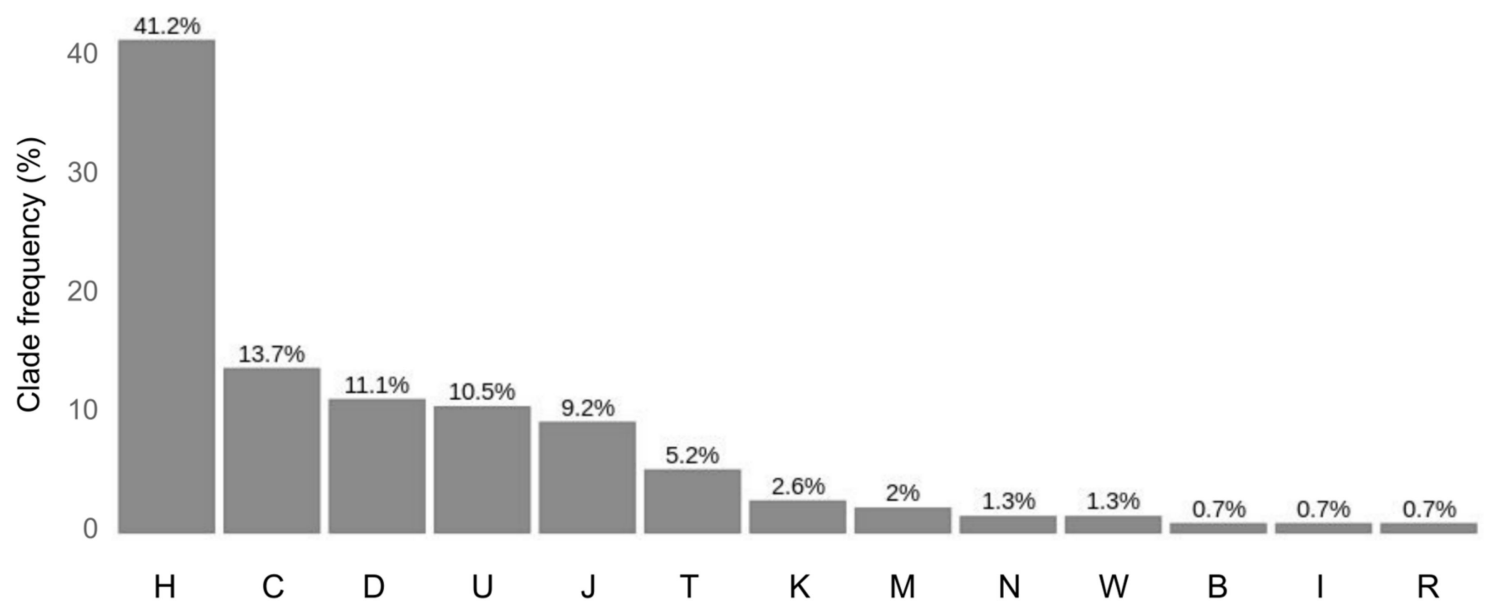

B

\begin{tabular}{|c|c|c|c|c|c|c|c|c|c|c|c|}
\hline Northwestern & & \multicolumn{4}{|c|}{$\mathrm{H}$} & & $\mathrm{K}$ & M & \multicolumn{3}{|c|}{$U$} \\
\hline Central & D & $\mathrm{H}$ & I & $\mathrm{J}$ & $\mathrm{K}$ & & $\mathrm{T}$ & & u & & \\
\hline Yakutia & B & & & D & & & & $\mathrm{H}$ & $\mathrm{J}$ & M & $\mathrm{N}$ \\
\hline Others & & $\mathrm{H}$ & & $\mathrm{J}$ & & $\mathrm{N}$ & $\mathrm{T}$ & $u$ & & W & \\
\hline
\end{tabular}

Figure 6. Haplogroup analysis with HaploGrep2. (A) Distribution of samples according to their superclade. (B) Distribution of samples from different regions according to their superclade. Others include Volga-Ural, Southern, Far Eastern and North Caucasian regions. The bars indicate the proportion of each superclade (percentage from the total number of samples in each region).

\subsection{The Vast Majority of Called Variants Are Reported to Be Benign According to ClinVar Database}

Mitochondrial variants were then annotated using ClinVar database [59]. It must be noted that some diagnoses from ClinVar database are yet to be validated. In this respect, we cannot draw compelling conclusions on the actual pathogenicity of the variants found. For common variants, we verified ClinVar diagnoses from independent sources wherever possible.

After ClinVar annotation, we have got 2791 variants. The depth of detected variants ranges from 1 to 647, where 4 is the median (Figure 7A). Variants with low depth $(<5)$ and variants located within homopolymers were filtered out as described before (Section 3.2) that reduced the number of variants to 1065. Notably, the low-depth regions and homopolymers are not the only factors that need to be considered, because depth represents a total number of reads and consists of reads with reference and alternative allele. Since a low amount of reads carrying the variant of the alternative allele can stem from the sequencing errors outside of homopolymer regions, we included an additional step of filtration, filtering out the variants with less than 4 reads supporting an alternative allele (Figure 7B). During this two-step filtration, 1817 (65.1\%) of all variants were discarded, all steps of the following analysis were performed for the remaining 974 (34.9\%) variants (Figure 7C). Analysis of the alternative allele frequencies (percentage of reads supporting an alternative allele) has revealed that the majority of variants detected-96.2\%-are represented by an alternative allele only and can be considered homoplasmic. In fact, the rate of homoplasmic variants is even higher if, by analogy with minimisation of possible sequencing errors by filtering out the variants with a low number of alternative reads, we accept that low representation of reads with a reference allele can also stem from sequencing errors. Since both of these two outcomes are equally likely, variants, where a reference allele is supported 
by a low number of reads (less than 4), can be also counted as homoplasmic. With this approximation, the percentage of homoplasmic variants rises to $98 \%$.

A

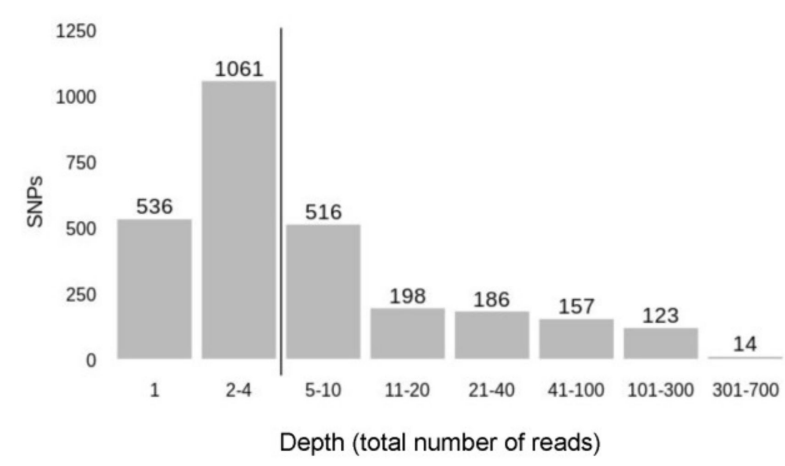

B

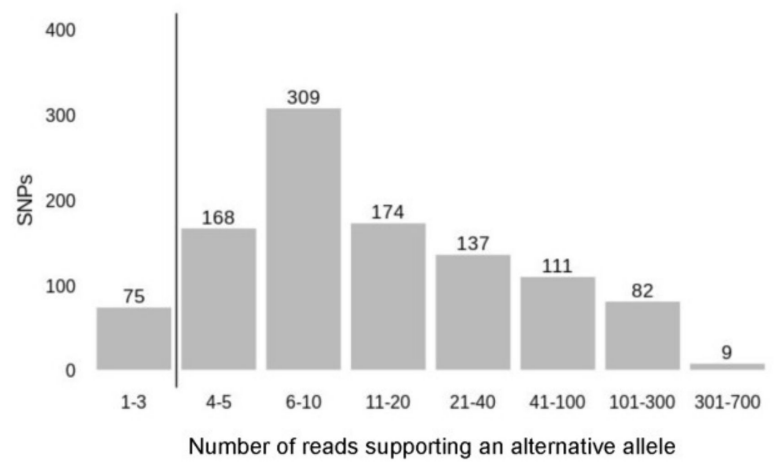

C

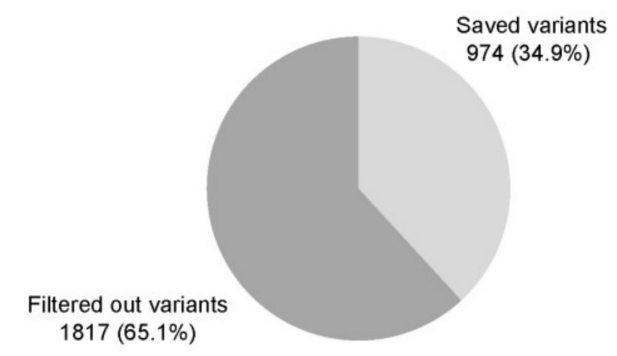

D

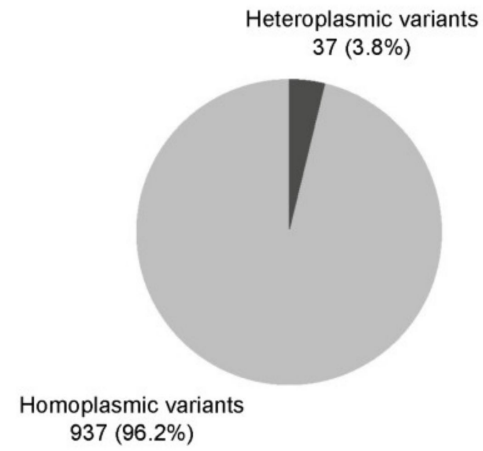

Figure 7. Filtration of the variants. (A) The first step of filtration or filtering out the variants with the lowest depths (less than 5), the vertical line sets the threshold. (B) The second step of filtration or filtering out the variant with the low number of reads carrying an alternative allele, the vertical line sets the threshold in 4 reads. (C) The distribution of variants after two steps of filtration. (D) The distribution of filtered variants by the number of reads supporting a reference allele-homoplasmic (all reads carry an alternative allele) and heteroplasmic (there are both reads with alternative and reference allele).

Analysis of clinical diagnoses associated with discovered variants has revealed that most of the variants were annotated with several different, sometimes even conflicting, diagnoses, because ClinVar database is constantly supplemented. Distribution of distinct diagnoses is presented in Figure 8A. As expected, Leigh syndrome ( $38.8 \%$ of all patients) and Familial cancer of breast (38.6\% of patients) are the most frequent diagnoses since they are presented by a large number of variants in ClinVar database. Five different variants are associated with familial cancer of breast-rs2853508 (85\% of all variants associated with familial cancer of breast), rs193302980 (6.5\%), rs527236177 (3.3\%), rs193302983 (3.3\%), rs193302985 (1.6\%). The first three variants are also linked with Leigh syndrome, according to new data. In total, Leigh syndrome was assigned to 12 distinct variants, most of which previously had another interpretation. Next, there are Neoplasm of ovary $(8.4 \%)$, resistance to Parkinson disease (4.4\%), Leber's optic atrophy (2.6\%) and Juvenile myopathy, encephalopathy, lactic acidosis and stroke (1.6\%). The remaining six diagnoses are represented with isolated variants and account for less than $1 \%$ of all variants. In total, $54.7 \%$ of variants analysed are provided with a clinical diagnosis from ClinVar (Figure 8B). Most of the variants without any diagnosis provided $(45.3 \%)$ are presumably associated with drug response. Drug response is the second-largest category, including $37.3 \%$ of all variants, but possible diagnoses associated with these variants are not discovered yet (Figure 8C). Most 
of the variants (51.5\%) are benign, $11 \%$ have conflicting interpretations of pathogenicity and only $2.3 \%$ (22) are pathogenic according to ACMG criteria. Among 22 pathogenic variants, $8(36.4 \%)$ are associated with nonsyndromic sensorineural mitochondrial deafness $(\mathrm{m} .961 \mathrm{~T}>\mathrm{G})$, one is reported to be associated with neoplasm of ovary $(\mathrm{m} .15511 \mathrm{~T}>\mathrm{C})$ and 13 $(59 \%)$ do not have clinical diagnosis provided: $\mathrm{m} .951 \mathrm{G}>\mathrm{A}(4), \mathrm{m} .980 \mathrm{~T}>\mathrm{C}(1), \mathrm{m} .1008 \mathrm{~A}>\mathrm{G}$ (2), m.8410C > T (1), m.11560A>G (1), m.14470T >A (1), m.15262T>C(1), m.15514T >C (1) and $\mathrm{m} .15833 \mathrm{C}>\mathrm{T}(1)$.

A

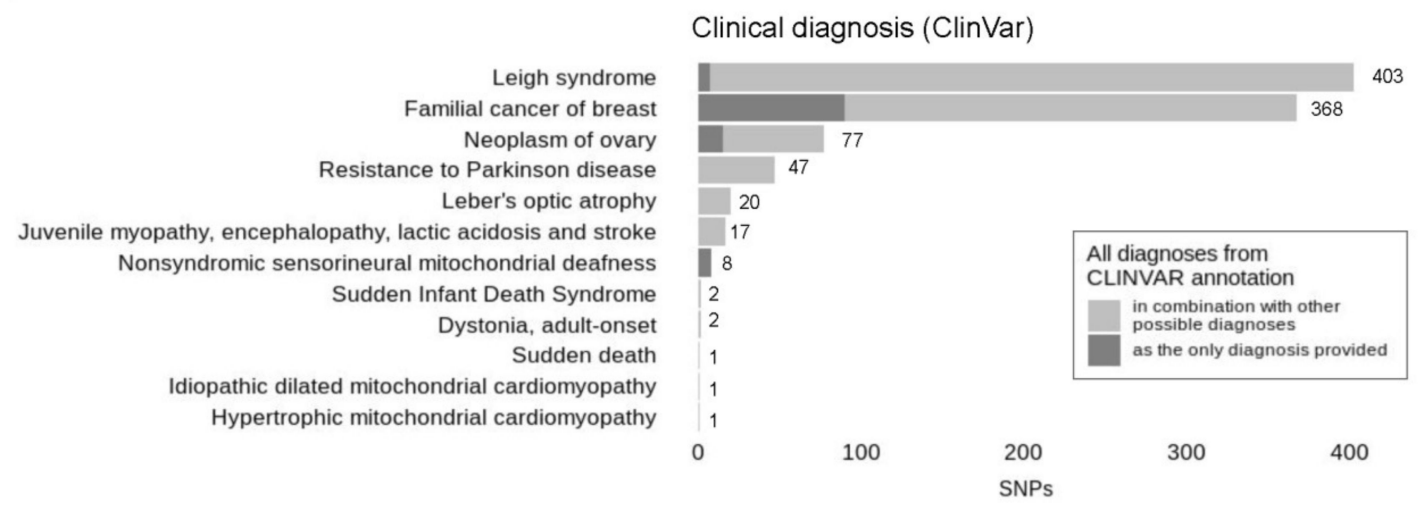

B

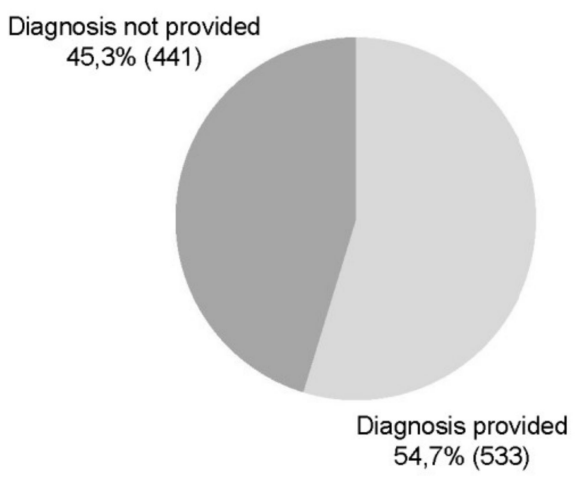

C

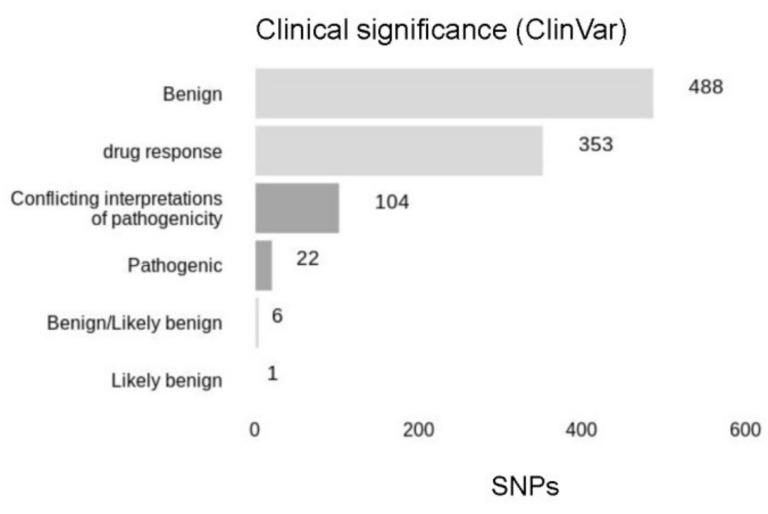

Figure 8. Clinical significance of detected SNPs. (A) All clinical diagnoses associated with analysed variants were collected and represented in descending order by the number of occurrences, cases, where the found diagnosis was the only diagnosis provided for this particular variant, are presented in dark grey colour, while the ones where the diagnosis was provided in combination with other possible interpretations are presented in light grey colour. (B) In total, clinical diagnosis was provided for $68.7 \%$ of analysed variants. (C) Distribution of detected SNPs by their clinical significance according to ClinVar. Light grey represents likely benign variants, dark grey represents pathogenic variants.

However, considering the high frequency of these variants among our samples, their pathogenicity is questionable.

\section{Discussion}

In this study, we explored the quantitative and qualitative composition of mtDNA pool of maternal cfDNA fraction from pregnant women, investigated how this composition is affected by transportation and storage conditions and experimented with utilising cfmtDNA to conduct mitochondrial analyses.

The sequencing of buffy coat DNA from selected samples has revealed that mtDNA pools from cfDNA and buffy coat do barely intersect. However, our result supports previous findings on the variability of mtDNA variant numbers between different tissues [10]. Since the risk of NUMT contamination is negligible, the observed differences may arise 
from the origin of DNA fragments in these pools since mtDNA of buffy coat is mostly presented by the mtDNA fragments of intact blood cells while the composition of cf-mtDNA fraction is more complex and includes foetal mtDNA and heterogeneous maternal mtDNA of apoptotic cells from different organs and systems of the body. In particular, the predominantly apoptotic origin of mtDNA fragments in cf-mtDNA fraction can be a possible explanation for the different set of variants in cf-mtDNA fraction, because apoptosis is known to be a common cell response to incorrect DNA replication or DNA damage [65]. The proximity of mtDNA to possible oxidative stress can cause accumulation of repair mismatches in mtDNA sequence $[66,67]$ and lead to cell death that allows alternate variants of mtDNA to add to cfDNA fraction in plasma. Moreover, some technical artefacts could not be discounted.

According to our data, the differences in the variant sets between cf-mtDNA and buffy coat DNA are observed in both Streck and EDTA samples. Generally, mtDNA content in Streck samples is higher due to degradation of leukocytes, so we observe more shared mitochondrial variants between cfDNA and buffy coat. In EDTA samples, conversely, we detect a smaller set of mtDNA variants. This can be attributed to low sequencing depth and incomplete mtDNA coverage resulting from low mtDNA content in EDTA samples. Our results allow us to conclude that, technically, Streck samples provide a more complete picture of mtDNA.

We showed that the size and composition of the mtDNA pool in samples are heavily dependent on conditions and time of transportation. Streck sample tubes are widely accepted and validated as a standard for NIPT [68]. Moreover, results by Hidestrand et al. present that blood collected into Streck BCT tubes had the total DNA level not changed within $72 \mathrm{~h}$ if shipped without freezing [63]. Still, the real shipping speed from distant regions such as Yakutia might be much slower and we show that mtDNA content is significantly increasing over time above the $72 \mathrm{~h}$ threshold (Figure $4 \mathrm{C}$ ). Our results suggest that degrading blood cells might be the main contributors to the mtDNA pool in samples subjected to long transportation. Maternal contamination is a major challenge in prenatal diagnosis [69,70], however, the tracking of contamination is not yet a common practice. Here we speculate that measuring the mtDNA level might allow us to make a rough estimate of the extent of sample contamination with degraded blood cells and check the purity of plasma which is important for foetal fraction estimation as an essential NIPT quality control component [71]. The low foetal fraction may be responsible for up to $50 \%$ of all failures as the excess of normal maternal DNA with a double set of chromosomes can mask the foetal aneuploidies and lead to false-negative results [72,73]. Here we show that shipping over 3 days results in higher mtDNA rate in samples, and the increase in mtDNA content leads to lower foetal fraction level thus potentially impacting NIPT results quality. There are techniques allowing the detection of maternal contamination in NIPT, such as single nucleotide polymorphism (SNP) oligonucleotide microarray analysis (SOMA) [74]. However, this method requires additional sequencing of a maternal sample which leads to increase in costs. Our results suggest mtDNA as a contamination marker that can be used for quality control to evaluate the extent of maternal cells degradation in samples.

The contamination effect must also be taken into account when using mtDNA content as a diagnostic sign of inflammation and other pathologies since blood cell mtDNA contamination can result in misleading measurements. However, increased share of blood cell DNA in cfDNA does not preclude population studies but is undesirable during NIPT since it can distort foetal fraction measuring.

We analysed mtDNA from 645 cfDNA samples and called over 7000 distinct variants, explored a set of mitochondrial variants called from cfDNA and tested its applicability for clinic and research purposes. Within the cell, the mtDNA-gDNA content ratio is less then 1:1000 [75], which is generally in line with mtDNA content we detected in cfDNA fraction (Figure 1A). It must be noted that while traditional genetic and clinical tests based on mtDNA analysis are conducted on amplified or deeply sequenced mtDNA [75,76], conducting similar tests within NIPT places significant limits caused by low coverage of 
cf-mtDNA [77]. Nevertheless, our results indicate that we can perform some mtDNA tests despite low coverage. The quantitative analysis of mtDNA pool has revealed that mtDNA in all samples with mean mtDNA sequencing depth exceeding $2 \times(43.7 \%)$ has more than $75 \%$ coverage, moreover, samples with mean mtDNA sequencing depth exceeding $4 \times(17.6 \%)$ have more than $95 \%$ of mtDNA covered (data not shown). To reach full mtDNA coverage, mean sequencing depth of mtDNA should be higher than $7-8$. The main advantage of our approach is that it does not require any additional steps of sample preparation and mtDNA amplification-we get results of mtDNA analysis as a by-product of an ordinary WGS NIPT protocol.

We checked the distribution of variants throughout the mitochondrial genome and revealed some hot and cold spots of variation. As expected, variants are accumulating within the control region of mtDNA supporting previous studies [39], but we also detected hotspots of variation outside of this region. Apart from non-coding regions, variants are accumulating in intergenic regions between 4 and 5,11 and $13 \mathrm{~kb}$. Regions between 5 and 7,8 and $10 \mathrm{~kb}$ carry significantly fewer variants. In order to figure out the reasons for this heterogeneity, we summed up all samples and explored the distribution of total coverage throughout the mitochondrial genome (data not shown). Cold spot regions have lower coverage, suggesting that some fragments of mtDNA are less frequent in cfDNA, probably due to GC sequencing bias [78] and selective mtDNA fragmentation [79].

Called variants can be used for mitochondrial haplogroup analysis. Haplogroup analysis showed haplogroups $\mathrm{H}(40.5 \%), \mathrm{C}(13.7 \%), \mathrm{D}(11.1 \%)$ and $\mathrm{U}(11.1 \%)$ to be the most common among the explored samples, which is typical for a mixture of Slavic and Asian populations presented in our data [43]. We compared our haplogroup frequencies with previous reports on mtDNA haplogroup frequencies of Russian and European populations. Haplogroup $\mathrm{H}$ was reported to be the top frequent mtDNA haplogroup in Russia with a population frequency of 37.3\% [80], which is highly consistent with our results-40.5\%. Our frequencies of haplogroups J (8.9\%), M (1.8\%), T (5.2\%) and W $(1.3 \%)$ are generally in line with previously reported frequencies $[80,81]$. Haplogroup $U(11.1 \%)$ is less frequent than reported $(\sim 17 \%)$. The presence of $C(13.7 \%)$ and $D(11.1 \%)$ haplogroups can be attributed to mongoloid admixture since mtDNA haplogroups $\mathrm{H}, \mathrm{U}, \mathrm{K}, \mathrm{J}, \mathrm{V}, \mathrm{I}$ and $\mathrm{W}$ are typical for west Eurasian populations, while A, B, C, D and M are mostly east Eurasian (Asian) mitotypes $[80,82]$. Indeed, $\mathrm{C}$ and $\mathrm{D}$ haplogroups in our data are mostly presented by samples from Yakutia. Moreover, we studied the distribution of the ancestral variants, especially common for Asian mitotypes, throughout different populations and found these variants to be the most frequent among Yakutian samples.

CfDNA has been already used for identifying mitochondrial haplogroups in previous studies [82]. However, it involved the cf-mtDNA amplification step, while we worked with unamplified cf-mtDNA. In the majority of cases, the set of variants was not enough for full haplogroup determination, so we worked with superclades. It has been empirically identified that reliable haplogroup determination requires hundreds of variants [83], which is also confirmed by our results. However, we can use samples with high mtDNA content, particularly the ones that were enriched with mtDNA as result of long transportation, to determine mitochondrial haplogroups to the level of specific subclades.

From a clinical perspective, mitochondrial SNPs called from NIPT samples are incredibly challenging to interpret. This is attributable to heteroplasmy and so-called 'bottleneckeffect' when a low amount of mutated mtDNA in the mother germline can result in a high percentage of mutated mitochondria in the foetus during embryonic development. Mitochondrial mutations occurring in the germline go through the transient heteroplasmic state, which resolves itself within a few generations [84]. In other words, it is not possible to establish any threshold for SNPs to exclude the possibility of disease development in further generations. For genomic SNPs, minor allele frequency (MAF) of less than 5\% indicates insignificant SNPs, while for mitochondrial SNPs this threshold should be much lower due to heteroplasmy [85]. It turns out that despite low sequencing depth we still can detect significant SNPs. However, mitochondrial variants called from the cfDNA 
pool of NIPT samples have mixed origin [12] and therefore their locations within a body cannot be established. Moreover, the accumulation of data on the clinical significance of mitochondrial variants is still in process, which often leads to false-positive results. Taken together, the robust prediction of mitochondrial diseases based on the analysis of variants called from NIPT samples is hardly possible, so clinical use of the method is limited. Still, detection of clinically significant variants might be important as a preliminary screening that can be an additional reason to direct a patient to undergo traditional mtDNA tests but cannot be considered as a self-sufficient clinical test for mitochondrial disease.

Nevertheless, in spite of limited diagnostic capability, called variants can still be used in population studies. The analysis of population frequencies of called variants showed that ancestral variants [62] m.15326A $<\mathrm{G}(22.3 \%), \mathrm{m} .750 \mathrm{~A}>\mathrm{G}(20.9 \%), \mathrm{m} .2706 \mathrm{~A}>\mathrm{G}(18.8 \%)$ and $\mathrm{m} .263 \mathrm{~A}>\mathrm{G}(15.0 \%)$ are the most common among studied patients. Frequent nonancestral variants are presented with microdeletions and microinsertions: m.9906delG (12.6\%), m.10151delA (6.8\%), m.9916delC (5.6\%), m.2193delT (4.3\%), m.9808insT (4.2\%).

NIPT is becoming a routine screening method and more and more samples are being tested annually all over the world. Our study is proof of principle that confirms the possibility of using NIPT samples in studies based on mtDNA analysis. MtDNA can be easily obtained from cfDNA sequencing data during the NIPT test and can be potentially used for haplogroup determination, quality control or stored for further studies. Currently, we do not have enough data to make valid clinical predictions, there must be a significant increase in sample size to develop the methods of mtDNA-based clinical diagnosis. Given the increasing popularity of NIPT, mtDNA from cfDNA data is a promising research object, which can add to our knowledge of the population structure and the possible pathogenicity of variants with unclear clinical significance.

Supplementary Materials: The following are available online at https:/ /www.mdpi.com/article/10 .3390/genes12050743/s1, Figure S1: Distribution of variants throughout the mitochondrial genome before (a) and after (b) filtering of homopolymers.

Author Contributions: Conceptualization, A.M., P.K. and A.G.; methodology, E.V., A.M., P.K.; software, A.M., P.K.; formal analysis, A.M., P.K.; investigation, E.V., O.T. (Olga Tarasenko), N.D., A.C.; resources, O.T. (Olga Talantova), A.K., D.I., E.S., O.B., T.I., A.S., N.M.; data curation, E.V.; writingoriginal draft preparation, A.M.; writing-review and editing, P.K., V.B., E.V., A.G.; visualization, A.M.; supervision, A.G., V.B., I.K.; project administration, A.G.; funding acquisition, I.K., A.G. All authors have read and agreed to the published version of the manuscript.

Funding: This work was support by FSBSI D.O. Ott Research Institute of Obstetrics, Gynaecology and Reproductology, project AAAA-A20-120041390028-0. The bioinformatics analysis relied on funds from Ltd NIPT, St. Petersburg, Russia.

Institutional Review Board Statement: The study was conducted according to the guidelines of the Declaration of Helsinki, and approved by the Local Ethics Committee of D.O. Ott Research Institute of Obstetrics, Gynecology and Reproduction. The committee operates in accordance with the rules of the GCP (good clinical practice). The date of approval: 16 July 2020.

Informed Consent Statement: Informed consent was obtained from all subjects involved in the study.

Data Availability Statement: The data are not publicly available due to due to commercial restrictions.

Acknowledgments: The authors would like to thank doctors for providing us with clinical data and information on pregnancy outcomes. Clinical information was kindly given by Kuzmicheva, I.A., Zaytseva, E.S. and Sedova, N.B. (Central Russian district) and Alekseeva, S.P., Alekseeva, T.L., Gotovtseva, G.Y., Gurinova, E.E., Nikolaeva, I.A., Sleptsov, A.N. and Sophronova, V.M. (Yakutia).

Conflicts of Interest: The authors declare no conflict of interests. 


\section{References}

1. Lo, Y.M.D.; Corbetta, N.; Chamberlain, P.F.; Rai, V.; Sargent, I.L.; Redman, C.W.; Wainscoat, J.S. Presence of fetal DNA in maternal plasma and serum. Lancet 1997, 350, 485-487. [CrossRef]

2. Suciu, I.D.; Toader, O.D.; Galeva, S.; Pop, L. Non-Invasive Prenatal Testing beyond Trisomies. J. Med. Life 2019, 12, 221-224. [CrossRef] [PubMed]

3. Carbone, I.F.; Conforti, A.; Picarelli, S.; Morano, D.; Alviggi, C.; Farina, A. Circulating Nucleic Acids in Maternal Plasma and Serum in Pregnancy Complications: Are They Really Useful in Clinical Practice? A Systematic Review. Mol. Diagn. Ther. 2020, 24, 409-431. [CrossRef] [PubMed]

4. Amaral, L.M.; Sandrim, V.C.; Kutcher, M.E.; Spradley, F.T.; Cavalli, R.C.; Tanus-Santos, J.E.; Palei, A.C. Circulating Total Cell-Free DNA Levels Are Increased in Hypertensive Disorders of Pregnancy and Associated with Prohypertensive Factors and Adverse Clinical Outcomes. Int. J. Mol. Sci. 2021, 22, 564. [CrossRef] [PubMed]

5. Gil, M.M.; Quezada, M.S.; Bregant, B.; Ferraro, M.; Nicolaides, K.H. Implementation of maternal blood cell-free DNA testing in early screening for aneuploidies. Ultrasound Obstet. Gynecol. 2013, 42, 34-40. [CrossRef]

6. Carbone, L.; Cariati, F.; Sarno, L.; Conforti, A.; Bagnulo, F.; Strina, I.; Pastore, L.; Maruotti, G.M.; Alviggi, C. Non-Invasive Prenatal Testing: Current Perspectives and Future Challenges. Genes 2020, 12, 15. [CrossRef]

7. Bedei, I.; Wolter, A.; Weber, A.; Signore, F.; Axt-Fliedner, R. Chances and Challenges of New Genetic Screening Technologies (NIPT) in Prenatal Medicine from a Clinical Perspective: A Narrative Review. Genes 2021, 12, 501. [CrossRef]

8. Newell, C.; Hume, S.; Greenway, S.C.; Podemski, L.; Shearer, J.; Khan, A. Plasma-derived cell-free mitochondrial DNA: A novel non-invasive methodology to identify mitochondrial DNA haplogroups in humans. Mol. Genet. Metab. 2018, 125, 332-337. [CrossRef]

9. Taylor, R.W.; Turnbull, D.M. Mitochondrial DNA mutations in human disease. Nat. Rev. Genet. 2005, 6, 389-402. [CrossRef]

10. Hazkani-Covo, E.; Zeller, R.M.; Martin, W. Molecular Poltergeists: Mitochondrial DNA Copies (numts) in Sequenced Nuclear Genomes. PLoS Genet. 2010, 6, e1000834. [CrossRef]

11. Goios, A.; Carvalho, A.; Amorim, A. Identifying NUMT contamination in mtDNA analyses. Forensic Sci. Int. Genet. Suppl. Ser. 2009, 2, 278-280. [CrossRef]

12. Jahr, S.; Hentze, H.; Englisch, S.; Hardt, D.; Fackelmayer, F.O.; Hesch, R.D.; Knippers, R. DNA fragments in the blood plasma of cancer patients: Quantitations and evidence for their origin from apoptotic and necrotic cells. Cancer Res. 2001, 61, 1659-1665. [PubMed]

13. Lood, C.; Blanco, L.P.; Purmalek, M.M.; Carmona-Rivera, C.; De Ravin, S.S.; Smith, C.K.; Malech, H.L.; Ledbetter, J.A.; Elkon, K.B.; Kaplan, M.J. Neutrophil extracellular traps enriched in oxidized mitochondrial DNA are interferogenic and contribute to lupus-like disease. Nat. Med. 2016, 22, 146-153. [CrossRef] [PubMed]

14. Kaczmarek, A.; Vandenabeele, P.; Krysko, D.V. Necroptosis: The Release of Damage-Associated Molecular Patterns and Its Physiological Relevance. Immunity 2013, 38, 209-223. [CrossRef]

15. Zhang, Q.; Raoof, M.; Chen, Y.; Sumi, Y.; Sursal, T.; Junger, W.; Brohi, K.; Itagaki, K.; Hauser, C.J. Circulating mitochondrial DAMPs cause inflammatory responses to injury. Nat. Cell Biol. 2010, 464, 104-107. [CrossRef]

16. Bae, J.H.; Jo, S.I.; Kim, S.J.; Lee, J.M.; Jeong, J.H.; Kang, J.S.; Cho, N.-J.; Kim, S.S.; Lee, E.Y.; Moon, J.-S. Circulating Cell-Free mtDNA Contributes to AIM2 Inflammasome-Mediated Chronic Inflammation in Patients with Type 2 Diabetes. Cells 2019, 8, 328. [CrossRef]

17. Agbor-Enoh, S.; Chan, J.L.; Singh, A.; Tunc, I.; Gorham, S.; Zhu, J.; Pirooznia, M.; Corcoran, P.C.; Thomas, M.L.; Lewis, B.G.; et al. Circulating cell-free DNA as a biomarker of tissue injury: Assessment in a cardiac xenotransplantation model. J. Hearth Lung Transplant. 2018, 37, 967-975. [CrossRef]

18. Liu, J.; Cai, X.; Xie, L.; Tang, Y.; Cheng, J.; Wang, J.; Wang, L.; Gong, J. Circulating Cell Free Mitochondrial DNA is a Biomarker in the Development of Coronary Heart Disease in the Patients with Type 2 Diabetes. Clin. Lab. 2015, 59, 661-667. [CrossRef]

19. Long, Y.; Zhang, Y.; Gong, Y.; Sun, R.; Su, L.; Lin, X.; Shen, A.; Zhou, J.; Caiji, Z.; Wang, X.; et al. Diagnosis of Sepsis with Cell-free DNA by Next-Generation Sequencing Technology in ICU Patients. Arch. Med. Res. 2016, 47, 365-371. [CrossRef]

20. Podlesniy, P.; Figueiro-Silva, J.; Llado, A.; Antonell, A.; Sanchez-Valle, R.; Alcolea, D.; Lleo, A.; Molinuevo, J.L.; Serra, N.; Trullas, R. Low cerebrospinal fluid concentration of mitochondrial DNA in preclinical Alzheimer disease. Ann. Neurol. 2013, 74, 655-668. [CrossRef]

21. Pyle, A.; Brennan, R.; Kurzawa-Akanbi, M.; Yarnall, A.J.; Thouin, A.; Mollenhauer, B.; Burn, D.J.; Chinnery, P.F.; Hudson, G. Reduced cerebrospinal fluid mitochondrial DNA is a biomarker for early-stage Parkinson's disease. Ann. Neurol. 2015, 78, 1000-1004. [CrossRef]

22. Cushen, S.C.; Sprouse, M.L.; Blessing, A.; Sun, J.; Jarvis, S.S.; Okada, Y.; Fu, Q.; Romero, S.A.; Phillips, N.R.; Goulopoulou, S. Cell-free mitochondrial DNA increases in maternal circulation during healthy pregnancy: A prospective, longitudinal study. Am. J. Physiol. Integr. Comp. Physiol. 2020, 318, R445-R452. [CrossRef]

23. Van Boeckel, S.R.; Davidson, D.J.; Norman, J.E.; Stock, S.J. Cell-free fetal DNA and spontaneous preterm birth. Reproduction 2018, 155, R137-R145. [CrossRef]

24. Busnelli, A.; Lattuada, D.; Ferrari, S.; Reschini, M.; Colciaghi, B.; Somigliana, E.; Fedele, L.; Ferrazzi, E. Mitochondrial DNA Copy Number in Peripheral Blood in the First Trimester of Pregnancy and Different Preeclampsia Clinical Phenotypes Development: A Pilot Study. Reprod. Sci. 2018, 26, 1054-1061. [CrossRef] 
25. Colleoni, F.; Lattuada, D.; Garretto, A.; Massari, M.; Mandò, C.; Somigliana, E.; Cetin, I. Maternal blood mitochondrial DNA content during normal and intrauterine growth restricted (IUGR) pregnancy. Am. J. Obstet. Gynecol. 2010, 203, 365.e1-365.e6. [CrossRef]

26. Qiu, C.; Hevner, K.; Enquobahrie, D.A.; Williams, M.A. A case-control study of maternal blood mitochondrial DNA copy number and preeclampsia risk. Int. J. Mol. Epidemiol. Genet. 2012, 3, 237-244.

27. Gilman-Sachs, A.; Dambaeva, S.; Garcia, M.D.S.; Hussein, Y.; Kwak-Kim, J.; Beaman, K. Inflammation induced preterm labor and birth. J. Reprod. Immunol. 2018, 129, 53-58. [CrossRef]

28. Palacín, M.; Alvarez, V.; Martín, M.; Díaz, M.; Corao, A.I.; Alonso, B.; Díaz-Molina, B.; Lozano, I.; Avanzas, P.; Morís, C.; et al. Mitochondrial DNA and TFAM gene variation in early-onset myocardial infarction: Evidence for an association to haplogroup $\mathrm{H}$. Mitochondrion 2011, 11, 176-181. [CrossRef]

29. Smart, A.; Bolnick, D.A.; Tutton, R. Health and genetic ancestry testing: Time to bridge the gap. BMC Med. Genom. 2017, 10, 3. [CrossRef]

30. Santoro, A.; Balbi, V.; Balducci, E.; Pirazzini, C.; Rosini, F.; Tavano, F.; Achilli, A.; Siviero, P.; Minicuci, N.; Bellavista, E.; et al. Evidence for Sub-Haplogroup H5 of Mitochondrial DNA as a Risk Factor for Late Onset Alzheimer's Disease. PLoS ONE 2010, 5, e12037. [CrossRef]

31. Ebner, S.; Lang, R.; Mueller, E.E.; Eder, W.; Oeller, M.; Moser, A.; Koller, J.; Paulweber, B.; Mayr, J.A.; Sperl, W.; et al. Mitochondrial Haplogroups, Control Region Polymorphisms and Malignant Melanoma: A Study in Middle European Caucasians. PLoS ONE 2011, 6, e27192. [CrossRef]

32. Chinnery, P.F. Mitochondrial Disorders Overview. In GeneReviews ${ }^{\circledR}$; Adam, M.P., Ardinger, H.H., Pagon, R.A., Wallace, S.E., Bean, L.J., Stephens, K., Amemiya, A., Eds.; University of Washington: Seattle, WA, USA, 1993.

33. Thorburn, D.R.; Rahman, J.; Rahman, S. Mitochondrial DNA-Associated Leigh Syndrome and NARP. In GeneReviews ${ }^{\circledR}$; Adam, M.P., Ardinger, H.H., Pagon, R.A., Wallace, S.E., Bean, L.J., Stephens, K., Amemiya, A., Eds.; University of Washington: Seattle, WA, USA, 1993.

34. Wallace, D.C.; Singh, G.; Lott, M.T.; Hodge, J.A.; Schurr, T.G.; Lezza, A.M.; Elsas, L.J., 2nd; Nikoskelainen, E.K. Mitochondrial DNA mutation associated with Leber's hereditary optic neuropathy. Science 1988, 242, 1427-1430. [CrossRef]

35. Melton, T. Mitochondrial DNA Heteroplasmy. Forensic Sci. Rev. 2004, 16, 1-20.

36. Gorman, G.S.; Chinnery, P.F.; DiMauro, S.; Hirano, M.; Koga, Y.; McFarland, R.; Suomalainen, A.; Thorburn, D.R.; Zeviani, M.; Turnbull, D.M. Mitochondrial diseases. Nat. Rev. Dis. Prim. 2016, 2, 16080. [CrossRef]

37. Schneider, S.; Excoffier, L. Estimation of Past Demographic Parameters from the Distribution of Pairwise Differences When the Mutation Rates Vary Among Sites: Application to Human Mitochondrial DNA. Genetics 1999, 152, 1079-1089. [CrossRef]

38. Nachman, M.W.; Crowell, S.L. Estimate of the Mutation Rate per Nucleotide in Humans. Genetics 2000, 156, 297-304. [CrossRef]

39. Michikawa, Y.; Mazzucchelli, F.; Bresolin, N.; Scarlato, G.; Attardi, G. Aging-Dependent Large Accumulation of Point Mutations in the Human mtDNA Control Region for Replication. Science 1999, 286, 774-779. [CrossRef]

40. Sharma, H.; Singh, A.; Sharma, C.; Jain, S.K.; Singh, N. Mutations in the mitochondrial DNA D-loop region are frequent in cervical cancer. Cancer Cell Int. 2005, 5, 34. [CrossRef]

41. Bahcall, O.G. mtDNA and genetic ancestry. Nat. Rev. Genet. 2015, 16, 128. [CrossRef]

42. Hammer, M.F. A recent common ancestry for human Y chromosomes. Nat. Cell Biol. 1995, 378, 376-378. [CrossRef] [PubMed]

43. Mitchell, S.L.; Goodloe, R.; Brown-Gentry, K.; Pendergrass, S.A.; Murdock, D.G.; Crawford, D.C. Characterization of mitochondrial haplogroups in a large population-based sample from the United States. Qual. Life Res. 2014, 133, 861-868. [CrossRef] [PubMed]

44. Pipek, O.A.; Medgyes-Horváth, A.; Dobos, L.; Stéger, J.; Szalai-Gindl, J.; Visontai, D.; Kaas, R.S.; Koopmans, M.; Hendriksen, R.S.; Aarestrup, F.M.; et al. Worldwide human mitochondrial haplogroup distribution from urban sewage. Sci. Rep. 2019, 9, 1-9. [CrossRef] [PubMed]

45. Budis, J.; Gazdarica, J.; Radvanszky, J.; Harsanyova, M.; Gazdaricova, I.; Strieskova, L.; Frno, R.; Duris, F.; Minarik, G.; Sekelska, M.; et al. Non-invasive prenatal testing as a valuable source of population specific allelic frequencies. J. Biotechnol. 2019, 299, 72-78. [CrossRef]

46. Pös, O.; Budis, J.; Kubiritova, Z.; Kucharik, M.; Duris, F.; Radvanszky, J.; Szemes, T. Identification of Structural Variation from NGS-Based Non-Invasive Prenatal Testing. Int. J. Mol. Sci. 2019, 20, 4403. [CrossRef]

47. Keyser, C.; Hollard, C.; Gonzalez, A.; Fausser, J.-L.; Rivals, E.; Alexeev, A.N.; Riberon, A.; Crubézy, E.; Ludes, B. The ancient Yakuts: A population genetic enigma. Philos. Trans. R. Soc. B Biol. Sci. 2015, 370, 20130385. [CrossRef]

48. Zlojutro, M.; Tarskaia, L.A.; Sorensen, M.; Snodgrass, J.J.; Leonard, W.R.; Crawford, M.H. Coalescent simulations of Yakut mtDNA variation suggest small founding population. Am. J. Phys. Anthropol. 2009, 139, 474-482. [CrossRef]

49. Duda, P.; Zrzavý, J. Human population history revealed by a supertree approach. Sci. Rep. 2016, 6, 29890. [CrossRef]

50. Wong, E.H.; Khrunin, A.; Nichols, L.; Pushkarev, D.; Khokhrin, D.; Verbenko, D.; Evgrafov, O.; Knowles, J.; Novembre, J.; Limborska, S.; et al. Reconstructing genetic history of Siberian and Northeastern European populations. Genome Res. 2016, 27, 1-14. [CrossRef]

51. Kivisild, T. Maternal ancestry and population history from whole mitochondrial genomes. Investig. Genet. 2015, 6, 1-10. [CrossRef]

52. McCormick, E.; Place, E.; Falk, M.J. Molecular Genetic Testing for Mitochondrial Disease: From One Generation to the Next. Neurotherapeutics 2012, 10, 251-261. [CrossRef] 
53. Wong, L.-J.C.; Scaglia, F.; Graham, B.H.; Craigen, W.J. Current molecular diagnostic algorithm for mitochondrial disorders. Mol. Genet. Metab. 2010, 100, 111-117. [CrossRef]

54. Miller, S.A.; Dykes, D.D.; Polesky, H.F. A simple salting out procedure for extracting DNA from human nucleated cells. Nucleic Acids Res. 1988, 16, 1215. [CrossRef]

55. Li, H.; Handsaker, B.; Wysoker, A.; Fennell, T.; Ruan, J.; Homer, N.; Marth, G.; Abecasis, G.; Durbin, R. 1000 Genome Project Data Processing Subgroup the Sequence Alignment/Map Format and SAMtools. Bioinformatics 2009, 25, 2078-2079. [CrossRef]

56. McKenna, A.; Hanna, M.; Banks, E.; Sivachenko, A.; Cibulskis, K.; Kernytsky, A.; Garimella, K.; Altshuler, D.; Gabriel, S.; Daly, M.; et al. The Genome Analysis Toolkit: A MapReduce framework for analyzing next-generation DNA sequencing data. Genome Res. 2010, 20, 1297-1303. [CrossRef]

57. Van Der Auwera, G.A.; Carneiro, M.O.; Hartl, C.; Poplin, R.; Del Angel, G.; Levy-Moonshine, A.; Jordan, T.; Shakir, K.; Roazen, D.; Thibault, J.; et al. From FastQ Data to High-Confidence Variant Calls: The Genome Analysis Toolkit Best Practices Pipeline. Curr. Protoc. Bioinform. 2013, 43, 11.10.1-11.10.33. [CrossRef]

58. Lindenbaum, P. JVarkit: Java-Based Utilities for Bioinformatics; Institut du Thorax: Nantes, France, 2015. [CrossRef]

59. Landrum, M.J.; Lee, J.M.; Riley, G.R.; Jang, W.; Rubinstein, W.S.; Church, D.M.; Maglott, D.R. ClinVar: Public archive of relationships among sequence variation and human phenotype. Nucleic Acids Res. 2014, 42, D980-D985. [CrossRef]

60. Human hg19 UCSC Genome Browser. v399. Available online: http://genome.ucsc.edu/cgi-bin/hgTracks?hgsid=845883669_B1 odJRHqogeppL15aTCtdmzGVmUl\&position=\&Submit=submit (accessed on 15 June 2020).

61. Weissensteiner, H.; Pacher, D.; Kloss-Brandstätter, A.; Forer, L.; Specht, G.; Bandelt, H.-J.; Kronenberg, F.; Salas, A.; Schönherr, S. HaploGrep 2: Mitochondrial haplogroup classification in the era of high-throughput sequencing. Nucleic Acids Res. 2016, 44, W58-W63. [CrossRef]

62. MITOMAP. Available online: https:/ / www.mitomap.org/MITOMAP/TopVariants (accessed on 4 June 2020).

63. Hidestrand, M.; Stokowski, R.; Song, K.; Oliphant, A.; Deavers, J.; Goetsch, M.; Simpson, P.; Kuhlman, R.; Ames, M.; Mitchell, M.; et al. Influence of Temperature during Transportation on Cell-Free DNA Analysis. Fetal Diagn. Ther. 2012, 31, 122-128. [CrossRef]

64. Risberg, B.; Tsui, D.W.; Biggs, H.; de Almagro, A.R.-V.M.; Dawson, S.-J.; Hodgkin, C.; Jones, L.; Parkinson, C.; Piskorz, A.; Marass, F.; et al. Effects of Collection and Processing Procedures on Plasma Circulating Cell-Free DNA from Cancer Patients. J. Mol. Diagn. 2018, 20, 883-892. [CrossRef] [PubMed]

65. Wang, J. DNA damage and apoptosis. Cell Death Differ. 2001, 8, 1047-1048. [CrossRef] [PubMed]

66. Mishra, M.; Kowluru, R.A. Retinal Mitochondrial DNA Mismatch Repair in the Development of Diabetic Retinopathy, and Its Continued Progression After Termination of Hyperglycemia. Investig. Opthalmology Vis. Sci. 2014, 55, 6960-6967. [CrossRef] [PubMed]

67. Nissanka, N.; Moraes, C.T. Mitochondrial DNA damage and reactive oxygen species in neurodegenerative disease. FEBS Lett. 2018, 592, 728-742. [CrossRef] [PubMed]

68. Wong, D.; Moturi, S.; Angkachatchai, V.; Mueller, R.; DeSantis, G.; Boom, D.V.D.; Ehrich, M. Optimizing blood collection, transport and storage conditions for cell free DNA increases access to prenatal testing. Clin. Biochem. 2013, 46, 1099-1104. [CrossRef]

69. Smith, M.; Lewis, K.M.; Holmes, A.; Visootsak, J. A Case of False Negative NIPT for Down Syndrome-Lessons Learned. Case Rep. Genet. 2014, 2014, 823504. [CrossRef]

70. Yaron, Y. The implications of non-invasive prenatal testing failures: A review of an under-discussed phenomenon. Prenat. Diagn. 2016, 36, 391-396. [CrossRef]

71. Hui, L.; Bianchi, D.W. Fetal fraction and noninvasive prenatal testing: What clinicians need to know. Prenat. Diagn. 2020, 40, 155-163. [CrossRef]

72. Hartwig, T.S.; Ambye, L.; Sørensen, S.; Jørgensen, F.S. Discordant non-invasive prenatal testing (NIPT) —A systematic review. Prenat. Diagn. 2017, 37, 527-539. [CrossRef]

73. Samura, O.; Okamoto, A. Causes of aberrant non-invasive prenatal testing for aneuploidy: A systematic review. Taiwan. J. Obstet. Gynecol. 2020, 59, 16-20. [CrossRef]

74. Norwitz, E.R.; Levy, B. Noninvasive Prenatal Testing: The Future Is Now. Rev. Obstet. Gynecol. 2013, 6, 48-62.

75. Ramos, A.; Santos, C.; Alvarez, L.; Nogués, R.; Aluja, M.P. Human mitochondrial DNA complete amplification and sequencing: A new validated primer set that prevents nuclear DNA sequences of mitochondrial origin co-amplification. Electrophoresis 2009, 30, 1587-1593. [CrossRef]

76. Yao, Y.; Nishimura, M.; Murayama, K.; Kuranobu, N.; Tojo, S.; Beppu, M.; Ishige, T.; Itoga, S.; Tsuchida, S.; Mori, M.; et al. A simple method for sequencing the whole human mitochondrial genome directly from samples and its application to genetic testing. Sci. Rep. 2019, 9, 17411-17417. [CrossRef]

77. Weerts, M.; Timmermans, E.; Van De Stolpe, A.; Vossen, R.; Anvar, S.; Foekens, J.; Sleijfer, S.; Martens, J. Tumor-Specific Mitochondrial DNA Variants Are Rarely Detected in Cell-Free DNA. Neoplasia 2018, 20, 687-696. [CrossRef]

78. Benjamini, Y.; Speed, T.P. Summarizing and correcting the GC content bias in high-throughput sequencing. Nucleic Acids Res. 2012, 40, e72. [CrossRef]

79. Lieber, T.; Jeedigunta, S.P.; Palozzi, J.M.; Lehmann, R.; Hurd, T.R. Mitochondrial fragmentation drives selective removal of deleterious mtDNA in the germline. Nat. Cell Biol. 2019, 570, 380-384. [CrossRef]

80. Morozova, I.Y.; Naumova, O.Y.; Rychkov, S.Y.; Zhukova, O.V. Mitochondrial DNA Polymorphism in Russian Population form Five Oblasts of the European Part of Russia. Russ. J. Genet. 2005, 41, 1040-1045. [CrossRef] 
81. Malyarchuk, B.A.; Derenko, M.V.; Grzybowski, T.; Lunkina, A.; Czarny, J.; Rychkov, S.; Morozova, I.; Denisova, G.; MiścickaSliwka, D. Differentiation of Mitochondrial DNA and Y Chromosomes in Russian Populations. Hum. Biol. 2004, 76, 877-900. [CrossRef]

82. Puzyrev, V.P.; Stepanov, V.A.; Golubenko, M.V.; Puzyrev, K.V.; Maksimova, N.R.; Kharkov, V.N.; Spiridonova, M.G.; Nogovitsyna, A.N. MtDNA and Y-chromosome lineages in the Yakut population. Russ. J. Genet. 2003, 39, 975-981. [CrossRef]

83. Kehdy, F.S.G.; Gouveia, M.H.; Machado, M.; Magalhães, W.C.S.; Horimoto, A.R.; Horta, B.L.; Moreira, R.G.; Leal, T.P.; Scliar, M.O.; Soares-Souza, G.B.; et al. Origin and dynamics of admixture in Brazilians and its effect on the pattern of deleterious mutations. Proc. Natl. Acad. Sci. USA 2015, 112, 8696-8701. [CrossRef] [PubMed]

84. Shoubridge, E.A. Mitochondrial DNA segregation in the developing embryo. Hum. Reprod. 2000, 15, 229-234. [CrossRef]

85. Zhang, P.; Samuels, D.C.; Wang, J.; Zhao, S.; Shyr, Y.; Guo, Y. Mitochondria single nucleotide variation across six blood cell types. Mitochondrion 2016, 28. [CrossRef] 